\title{
Using the social ecological model to build a path analysis model of physical activity in a sample of active US college students
}

\author{
Jonathan J. Stewart \\ West Virginia University, jjstewart@mix.wvu.edu
}

Follow this and additional works at: https://researchrepository.wvu.edu/etd

Part of the Health Psychology Commons, and the Sports Studies Commons

\footnotetext{
Recommended Citation

Stewart, Jonathan J., "Using the social ecological model to build a path analysis model of physical activity in a sample of active US college students" (2020). Graduate Theses, Dissertations, and Problem Reports. 7652.

https://researchrepository.wvu.edu/etd/7652

This Dissertation is protected by copyright and/or related rights. It has been brought to you by the The Research Repository @ WVU with permission from the rights-holder(s). You are free to use this Dissertation in any way that is permitted by the copyright and related rights legislation that applies to your use. For other uses you must obtain permission from the rights-holder(s) directly, unless additional rights are indicated by a Creative Commons license in the record and/ or on the work itself. This Dissertation has been accepted for inclusion in WVU Graduate Theses, Dissertations, and Problem Reports collection by an authorized administrator of The Research Repository @ WVU. For more information, please contact researchrepository@mail.wvu.edu.
} 
Using the social ecological model to build a path analysis model of physical activity in a sample of active US college students

\section{Jonathan Stewart, M.S.}

Dissertation submitted to the College of Physical Activity and Sport Sciences at West Virginia University in partial fulfillment of the requirements for the degree of

Doctorate of Philosophy in Kinesiology

With an emphasis in Sport and Exercise Psychology

Sam Zizzi, Ed.D. (Committee Chair)

Christa Lilly, Ph.D.

Scott Barnicle, Ph.D.

Jack C. Watson II, Ph.D.

Department of Sport Sciences

Morgantown, West Virginia

2019

Keywords: physical activity, alcohol use, college, social ecological model, achievement goal Copyright 2019 Jonathan Stewart 


\begin{abstract}
Using the social ecological model to build a path analysis model of physical activity in a sample of active US college students
\end{abstract}

Jonathan Stewart, M.S.

Objective: To examine how achievement goal orientation, perceived barriers and benefits, selfefficacy, on-campus residence, transportation, and binge drinking impact physical activity. Participants: Five hundred and twenty (70.23\% female) college students participated in the study during Fall 2014. Methods: Students completed an online questionnaire that measured environmental and psychosocial factors, and physical activity behaviors. Results: A path analysis revealed that self-efficacy, episodes of binge drinking, use of active transportation, and use of public transportation all had significant direct effects on physical activity. Meanwhile, perceived barriers had a significant negative direct effect on physical activity. Conclusion: Results indicate that both environmental and psychological factors influence engagement in physical activity. 


\section{Acknowledgements}

I would like to start by thanking my family for being a consistent source of support and motivation. Clay and Logan, you have both helped keep me motivated and grounded throughout this journey. I am incredibly proud of you both. Mom and Dad, you have both taught me so much. To my whole family, you all have given me so much over the years and I appreciate you all more than you know.

Next I would like to thank my WVU family for making this adventure a memorable one. Thank you for listening to me when I needed to vent, for teaching me to dress in the cold weather, for the early morning office chats, and the company during those late night writing sessions. You have all left a permanent imprint on my life in one way or another. I am a better person for the time that we all had together. Aaron and Zenzi. Thank you for being consistent sources of guidance, motivation, and laughs no matter the physical distance. Carra, thanks for challenging me and providing wisdom I didn't even know I needed. I would also like to thank all of my Public Health colleagues and peers. My experiences in Public Health have shaped my view of the world in ways I never could have imagined.

To the WVU and SEP faculty, thank you for giving me the opportunity to pursue my dream. Your trust and faith in me helped me grow into the person that I am today. Dr. Zizzi, thank you for your unwavering support, especially near the end. Your trust in me helped me learn to trust myself. Thank you for meeting me at the base of the mountain and guiding me to the top. Dr. Lilly, thank you for your guidance, support, and (perhaps most of all) your patience. Your willingness to go above and beyond is greatly appreciated. Dr. Watson, thank you for being there throughout my time in Morgantown and not letting me disappear once I left town. Dr. Barnicle, thank you for your support and for challenging me take a different perspective. Dr. Etzel, your wise words continue to resonate with me both personally and professionally. Ashley, you helped me find my passion in applied work and reminded me why I wanted to study SEP in the first place. For that I will be forever grateful. Dr. Giacobbi, thank you helping me to develop my research skills as I was first embarking on this $\mathrm{PhD}$ journey and for helping introduce me to the world of Public Health.

I would also like to thank all of colleagues at the SRC. Nancy, thank you for always providing a break from academia, your mentorship, and professional and general life guidance. You always said what I needed to here, regardless of whether or not I wanted to hear it. I'll always be grateful for that and for everything you have done for me.

Last, but certainly not least, thank you to my R2 friends and family. Hayley, James, Brittney, Matt, Will, and Patrick. Thank you for being a steady source of support, motivation, a sounding board, and for putting up with me as I finished this journey. 


\section{Table of Contents}

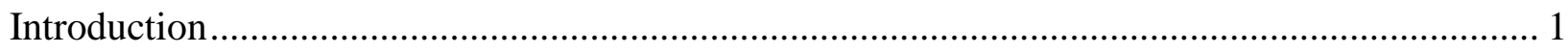

Socioecological Model ................................................................................................. 4

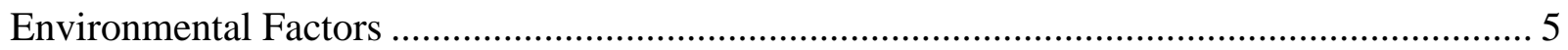

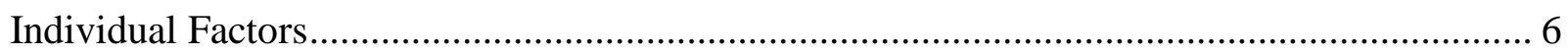

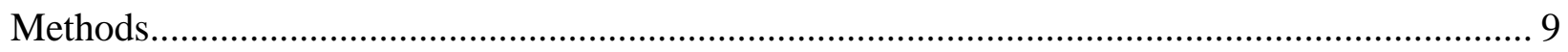

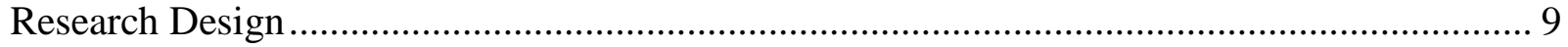

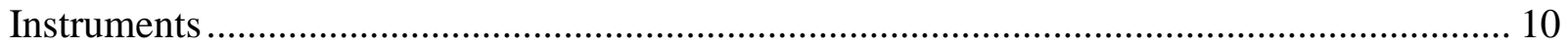

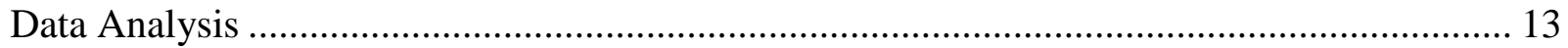

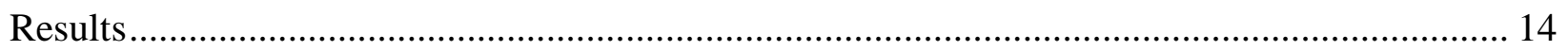

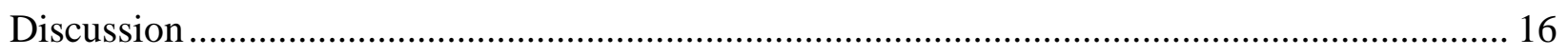

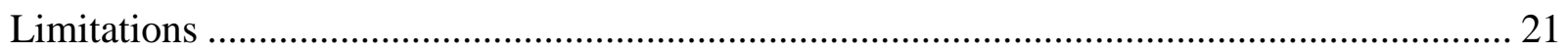

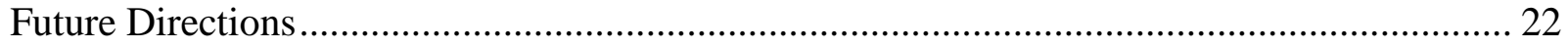

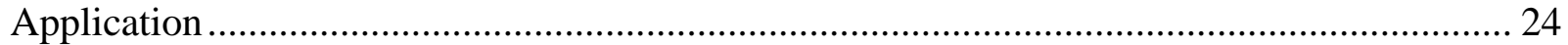

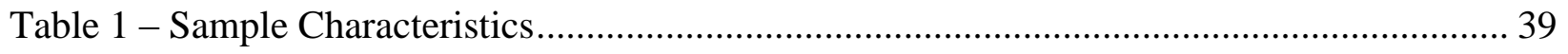

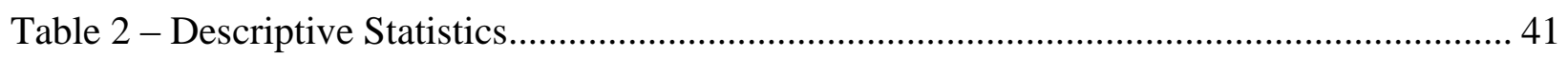

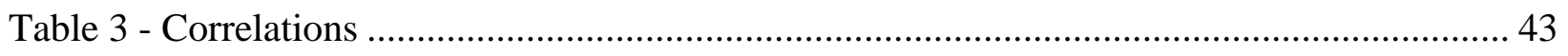

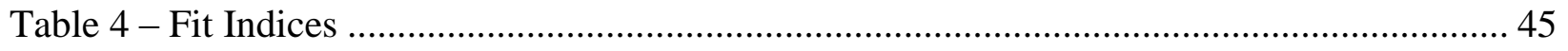

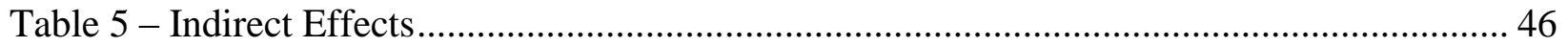

Figure 1 - Hypothesized Model......................................................................................... 47

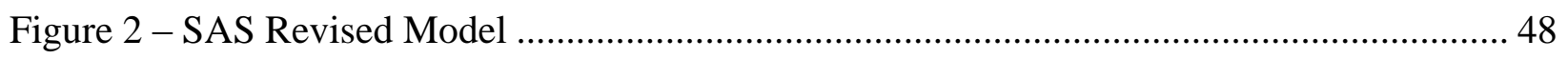

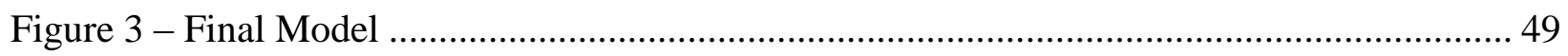

Appendix A. Extended Review of the Literature .................................................................... 50

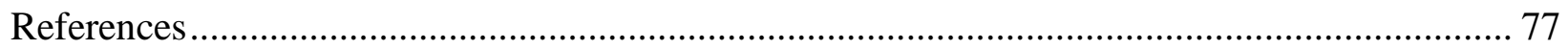




\section{Introduction}

Physical inactivity and alcohol consumption are two risk factors commonly associated with the development of a number of chronic diseases and premature death (Lee et al., 2012; Warburton et al., 2006; World Health Organization, 2018). Alcohol consumption, including an increased number of daily drinks, drinking frequency, and heavy episodic drinking, has been associated with academic problems, injuries, and risky behavior in college students and emerging adults (18-24 years of age) (Hingson, 2017; Kuperberg \& Padgett, 2017; Rinker et al., 2016). In contrast, physical activity can serve as a protective factor and reduce the risk of developing chronic diseases such as diabetes, heart disease, and colon cancer (Kyu et al., 2016; Lee, Sesso, Oguma, \& Paffenbarger, 2003). Individuals who are physically active in early adulthood (18-22 years old) are more likely to be physically active later in life (Nogueira et al., 2009). Thus, physical activity behaviors and increased frequency of drinking during the college years (i.e. generally 18-24 years of age) have the potential to have lasting impacts later in life.

The American College Health Association (2019) defined recommended levels of physical activity as a minimum of 30 minutes of moderate intensity cardio or aerobic exercise on 5 or more days per week, or at least 20 minutes of vigorous cardio or aerobic exercise on 3 or more days per week. The American College Health Association (2019) reported data from 54,497 students in the Spring 2019 National College Health Assessment II (ACHA-NCHA II). In this large sample, $46.2 \%$ of undergraduate students met recommended levels of exercise based on self-reported data (American College Health Association, 2019). The ACHA semi-annual survey includes items assessing a wide variety of health- and academic-related variables using a comprehensive self-report survey. Colleges and universities use this data to compare selfreported behaviors on their campus to national norms. 
One of the most common health behaviors studied along with physical activity in US college students is alcohol consumption. The American College Health Association (2019) recently stated that $55.8 \%$ of undergraduate college students reported consuming an alcoholic beverage within the previous 30 days. Among the students who consumed alcohol, $33.3 \%$ reported doing something they regretted while drinking in the past 12 months.

Furthermore, Soedamah-Muthu, De Neve, Shelton, Tielemans, and Stamatakis (2013) have reported a joint association between alcohol consumption, level of physical activity, and risk of cardiovascular mortality and all-cause mortality. Physical activity was measured in METhours/week. METs (or metabolic equivalents) represent energy expenditure at different intensities (i.e. 1 MET represents sitting quietly). Alcohol was measured in units ( 1 unite $=8 \mathrm{~g}$ of ethanol or approximately $4 \mathrm{oz}$. of wine or $8 \mathrm{oz}$. of beer). When physical activity was low (.1 to 5 MET-hours/week for males and .1 to 4 MET-hours/week for females) and alcohol consumption was high (>35 units/week for males and >21 units/week for females) there is an increased risk of cardiovascular mortality (HR 1.95) and all-cause mortality (HR 1.64). However, the researchers found that when physical activity was high ( $\geq 5$ MET-hours/week for males and $\geq 4$ METhours/week for females), high alcohol intake was not linked to increased risk of cardiovascular mortality. Thus, both alcohol intake and physical activity are important for reducing risk of allcause mortality and cardiovascular mortality. However, given that high alcohol intake was not associated with increased risk of cardiovascular mortality in the presence of high levels of physical activity, physical inactivity may be a larger contributing factor to the risk of cardiovascular mortality than alcohol consumption.

Contrary to what may be expected, level of physical activity is commonly associated with alcohol consumption in college students. Students who self-reported consumption of alcohol within the past 30 days were $40 \%$ more likely to have used the campus recreation facility 
compared to those who had not consumed alcohol (Miller, Noland, Rayens, \& Staten, 2008). The amount of alcohol consumed while binge drinking $(r=.13)$ and self-reported level of drinking $(r=.08)$ have been found to be positively associated (though weakly) with leisure time physical activity (Stuntz, Smith, \& Vensel, 2017). Graupensperger, Wilson, Bopp, and Blair Evans (2018) found that alcohol consumption was associated with vigorous, but not moderate, physical activity across a six month study. Despite these associations, the underlying mechanism for the relationship between alcohol consumption and physical activity is unclear. Some hypothesize that students may engage in physical activity to compensate for the alcohol consumed while drinking (Abrantes et al., 2017; Graupensperger et al., 2018).

A variety of other factors have been linked to alcohol consumption in college students, including location of residence, social influence, and alcohol related norms (Abrantes et al., 2017; Arterberry, Smith, Martens, Cadigan, \& Murphy, 2014; Graupensperger et al., 2018; Weitzman, Nelson, \& Wechsler, 2003; Yoon, Kim, \& Lee, 2014). For example, researchers have investigated the relationship between protective behavioral strategies, alcohol related norms, and alcohol behavior in a sample of college students (Arterberry et al., 2014). The researchers noted that social norms, such as perceived alcohol consumption among other students, were positively associated with alcohol use. These studies did not examine important environmental factors in relation to physical activity, such as transportation.

Given the positive association between alcohol consumption and levels of physical activity, it is important to have a better understanding of this relationship, and the factors that impact both behaviors to reduce alcohol consumption without reducing physical activity. Therefore, there is a need to approach these behaviors through a framework such as the social ecological model. This will allow for the inclusion of different factors, at multiple levels, that influence engagement in health behaviors. 


\section{Socioecological Model}

The simple provision of physical activity recommendations by organizations and the government has been ineffective at increasing physical activity behaviors at the population level (Guthold et al., 2018; Pratt et al., 2015; Sallis et al., 2016; Schwartz et al., 2019). Despite increased awareness of these recommendations, from 2001 to 2016, the level of insufficient physical activity in high income countries increased from $31.6 \%$ to $36.8 \%$ (Guthold et al., 2018). Thus, researchers have emphasized the application of theoretical frameworks to the study of physical activity (R. E. Rhodes et al., 2019). For example, in a recent review, researchers summarized randomized (RCT) and non-randomized (NRCT) control trials that promoted physical activity in university students (Maselli et al., 2018). Researchers utilized more than one theory to inform intervention design in multiple trials. All but one of the effective interventions addressed multiple components of physical activity behavior, however, the majority of these studies focused on individual or interpersonal factors and excluded environmental factors, which are often the most dynamic and complex in nature.

The central theory of a social ecological model is that behavior is the result of various nested levels of interpersonal, intrapersonal, and environmental influences (Bronfenbrenner, 1977; Sallis et al., 2008; Spence \& Lee, 2003). Over time, physical activity researchers have begun to favor the incorporation of multiple levels of influence. Bauman et al. (2012) examined reviews of physical activity with a focus on individual, interpersonal, environmental, regional or national policies, and global factors across a wide array of age groups and cultures. The authors of this review note that both environmental and personal factors may influence physical activity behavior. Thus, the inclusion of multiple environmental, psychosocial, and behavioral factors may provide additional insight into physical activity behavior beyond a more singular focus (Bauman et al., 2012; Sallis et al., 2006; Spence \& Lee, 2003). To accomplish this goal, 
researchers may need to use more advanced statistical methods that allow several factors across levels to be evaluated simultaneously.

\section{Environmental Factors}

Researchers have examined environmental factors associated with physical activity by including the relationship between residence (on/off campus), distance of residence from campus recreation centers, and level of physical activity (Allen \& Ross, 2013; Castle, Alman II, Kostelnik, \& Smith, 2015; Essiet, Baharom, Shahar, \& Uzochukwu, 2017; Miller et al., 2008; Reed \& Phillips, 2005; Staten, Miller, Noland, \& Rayens, 2005; Watson, Ayers, Zizzi, \& Naoi, 2006; Yoon et al., 2014). Students who lived on-campus or within one mile of the campus recreation facility were more likely to use the facility compared to those who lived off-campus or over one mile away (Castle et al., 2015; Watson et al., 2006) and typically report higher levels of physical activity compared to those who live off campus or further away (Miller et al., 2008; Staten et al., 2005; Yoon et al., 2014). In a random sample of 899 undergraduate students, those who lived on campus were $44 \%(\mathrm{OR}=1.44)$ more likely to use the facility compared to those who lived off campus (Miller et al., 2008). In short, students living on campus tend to engage in higher levels of physical activity compared to those living off-campus.

Environmental factors, such as location of residence (e.g. on-campus), are not only positively associated with physical activity, but have also been associated with increased alcohol consumption in college students (Castle et al., 2015; Staten et al., 2005; Yoon et al., 2014). Environmental factors can contribute to first year students beginning to binge drink (e.g. 5 or more drinks for males) in college. Weitzman and colleagues (2003) used national data to determine factors associated with binge drinking in freshman students. They found that first year students who lived in coed on-campus $(\mathrm{OR}=1.90)$ or Greek housing $(\mathrm{OR}=2.85)$ were significantly more likely to begin binge drinking compared to students who lived off-campus 
with a roommate $(\mathrm{OR}=.82)$ or with parents $(\mathrm{OR}=.40)$. Similarly, in another study, the authors reported female students who lived on-campus consumed more alcoholic beverages than female students who lived off-campus (Yoon et al., 2014).

In line with the socioecological framework, community and individual level factors such as transportation, self-efficacy and motivation may also play an important role in determining physical activity behavior. For example, in a study with college students in Ireland, Murphy and colleagues (2019) found that students who had a longer travel time (lived 10 minutes further from their university) were less likely to be classified as active commuters $(\mathrm{OR}=.59)$, participate in physical activity only at the university $(\mathrm{OR}=.80)$, or fall in the high physically active cluster $(\mathrm{OR}=.58)$. At the same time, an increase in motivation (e.g. feeling motivated to be physically active) increased the likelihood that students would participate in physical activity only at the university $(\mathrm{OR}=1.13)$ or be placed in the high active cluster $(\mathrm{OR}=1.27)$. In other words, for every one unit increase on the Likert scale in motivation, students were $27 \%$ more likely to be classified in the high active cluster. This may be especially important given the negative relationship between living further from campus and physical activity. Therefore, in addition to modes of transportation, motivation may be an important intrapersonal factor that can influence behavior in conjunction with environmental factors.

\section{Individual Factors}

Researchers have reported that motivation may facilitate beneficial beliefs about physical activity and lead to sustained behavior in college students (Kilpatrick et al., 2003; Watson et al., 2006; Zizzi et al., 2006). Achievement goal theory describes how individuals define success in specific achievement contexts, such as exercise, and thus how they are motivated to reach their goals (Nicholls, 1989; Roberts et al., 1998). In achievement goal theory, achievement goals aren't just targets, rather, they represent an orientation toward tasks that include associated views 
about success, effort, ability, and purpose (Pintrich, 2000). Specifically, task-oriented motivation (success occurs with learning and mastery) was positively associated with exercise intensity, years exercising, and exercise enjoyment. On the other hand, ego orientation (success is defined through comparison to others or some standard) was not significantly correlated to these constructs (Kilpatrick et al., 2003).

Moreover, research shows that as college students transition toward maintenance (i.e., sustain recommended guidelines of 150 minutes of physical activity for more than 6 months) of physical activity, level of task focus continues or increases, while reliance on ego reference cues decreases (Zizzi et al., 2006). In a study involving 569 college students, Zizzi et al. (2006) found that, students who exercised regularly were more likely to be in the high task/high ego group than the low task/low ego group. Additionally, task orientation has been associated with the belief that success was related to effort, interest, and adaptive achievement strategies (Biddle et al., 2003; Duda \& Nicholls, 1992). Thus, a task involvement may yield sustained effort, more adaptive behaviors, and persistence in physical activity engagement compared to ego involvement, which has been a consistent finding in the literature (Biddle et al., 2003; Duda, 1989; Duda \& Nicholls, 1992; Kilpatrick et al., 2003).

In addition to motivation, self-efficacy is often found to be related to level of physical activity (Maselli et al., 2018; Young et al., 2014). Self-efficacy refers to an individual's belief in their ability to take the actions necessary to cope with a situation or achieve a desired outcome (Bandura, 1982) and has been associated with increased physical activity in college students (Shaikh et al., 2018). Specifically, these researchers observed that exercise self-efficacy was positively associated with days of strenuous physical activity.

Two factors that may influence an individual's self-efficacy and level of physical activity are perceived benefits and barriers (Bandura, 1982; Grubbs \& Carter, 2002; Horacek et al., 2018; 
King et al., 2014). Common benefits of physical activity reported by college students include improved physical appearance, physical fitness, and health (Grubbs \& Carter, 2002; King et al., 2014). College students also face a number of barriers to physical activity such as lack of knowledge, self-efficacy, time, and resources (Sukys et al., 2019). In a sample of 480 college students, King and colleagues (2014) noted that perceived benefits were positively associated with vigorous physical activity, while perceived barriers were negatively associated with vigorous physical activity. However, other researchers have suggested that the impact of perceived barriers outweighs the impact of perceived benefits on physical activity (Hurley et al., 2018). Thus, further investigation is needed to clarify the role of perceived benefits and barriers in determining physical activity behavior.

Although previous research has established the relationship between psychological and environmental factors and physical activity, they have traditionally focused on these factors separately from each other and/or have not used path analysis to develop a model of these factors. Thus, the purpose of the current study is to utilize a socioecological framework to investigate the relationship between environmental and psychological correlates of physical activity. More specifically, we will examine how achievement goal orientation, perceived barriers, perceived benefits, self-efficacy, on-campus residence, transportation, and binge drinking are related to physical activity. A secondary purpose is to explore the interactions between achievement goal orientation and barrier self-efficacy, as well as the interactions between on-campus residence, transportation, and binge drinking. Figure 1 represents a diagram of the proposed model.

Perceived benefits, barriers, and self-efficacy are associated with physical activity behavior (Grubbs \& Carter, 2002; King et al., 2014; Maselli et al., 2018; Shaikh et al., 2018). Individuals with a high task orientation may persist in the face of challenges and barriers to 
physical activity (Biddle et al., 2003; Kilpatrick et al., 2003). Thus, the relationship between achievement orientation and physical activity may be mediated by perceived barriers and benefits. Previous researchers have established a positive association between living on-campus, alcohol consumption, and physical activity, as well as between alcohol consumption and physical activity (Castle et al., 2015; Graupensperger et al., 2018). Thus, it was hypothesized that alcohol consumption and transportation would mediate the relationship between living on-campus and physical activity. In summary:

- Task and ego motivations were proposed to be negatively associated with perceived barriers and positively associated with perceived benefits

- Task and ego motivations were proposed to be positively associated with physical activity

- Location of residence was proposed to be positively associated with alcohol consumption, use of public and active transportation, and physical activity

- Self-efficacy, alcohol consumption, and use of active and public transportation were proposed to be positively associated with physical activity engagement

- Self-efficacy was expected to mediate the relationship between perceived barriers, perceived benefits, and physical activity

- Alcohol consumption and transportation were expected to mediate the relationship between location of residence and physical activity

\section{Methods}

\section{Research Design}

The present study completed a secondary analysis of data collected via a cross sectional survey. Self-reported data were collected from 629 university students. The research design was quantitative and correlational in nature. 


\section{Instruments}

The present survey was a modified version of a previously published survey that was used with similar populations (Zizzi et al., 2004, 2006). The final survey included a total of 96 questions that assessed residence (on or off-campus), transportation, physical activity, forms of exercise, barriers to exercise, confidence, support, primary reason for campus recreation facility use, desired facility improvements, goal orientation, alcohol use, and demographic information. During survey development, input was sought from experts in the field as well as staff from the university’s Student Recreation Center’s Wellness staff on several items.

Achievement goal orientation. Achievement goal orientation refers to how an individual defines personal success in specific achievement contexts and thus their motivation to reach their goal success (Nicholls, 1989; Roberts et al., 1998). The Perception of Success Questionnaire for Exercise (POSQ-E; Zizzi et al., 2006) was used to measure goal orientation. The POSQ-E consists of 11-items (6 task orientation and 5 ego orientation) measured on a 4-point Likert type scale. The items are averaged to determine task and ego orientation. The higher the score on the task orientation subscale, the more the individual defines their success by personal mastery and improvement. The higher the score on the ego orientation subscale, the more the individual defines their success as outperforming others or some standard. A sentence stem of "When exercising, I feel most successful when..." was used for each item in the POSQ-E (Zizzi et al., 2006). In previous research the two subscales of the POSQ-E combined to explain approximately $65 \%$ of variance and had good internal reliability with alpha values of .87 (task) and .88 (ego). The questionnaire has also demonstrated convergent validity with stages of change for exercise participation and factor validity. Average item response was used for each subscale, task and ego. 
Binge drinking. Binge drinking is defined as the consumption of 5 or more alcoholic beverages for males, (4 or more for females) in one sitting (ACHA, 2014). Similarly, the Substance Abuse and Mental Health Services Administration states that binge drinking occurs on one occasion or over the course of a couple of hours (National Institute on Alcohol Abuse and Alcoholism, 2017). An alcoholic drink was defined for the participants as 12 ounces of beer, 5 ounces of wine, or 1.25 ounces of hard alcohol. The questionnaire contained four items modeled after the ACHA (2014) questions (last 30 days) and the definition of binge drinking. A binary (yes/no) question was used to assess if the participants consumed alcohol in the past 30 days. For the purpose of this study, binge drinking was assessed by asking how many times they consumed 5 or more drinks (4 drinks for females) in one sitting over the past two weeks. The number of hours for "one sitting" was not defined for participants.

Physical activity. Physical activity can be defined as any physical movement that leads to an increase in energy output (R. E. Rhodes et al., 2017). Examples and definitions for moderate (brisk walking, gardening, activities that cause small increases in breathing or heart rate) and vigorous (running, aerobics, activities that cause large increases in your breathing or heart rate) physical activity were provided for participants. Physical activity was measured with modified questions from the Behavioral Risk Factor Surveillance System Survey Questionnaire (CDC, 2014). These questions included the number of days they engage in physical activity (moderate or vigorous) for at least 10 minutes and on those days, the time in minutes spent per day engaging in moderate or vigorous activity. Number of days of physical activity was multiplied by minutes to determine weekly minutes of physical activity. Weekly minutes of physical activity was rescaled (divided by 100) prior to running path analysis.

Barriers to physical activity. Participants were asked how often different barriers interfere with or prevent them from exercising. Perceived barriers to physical activity were 
assessed using a 4-point Likert type scale (1-Never to 4-Frequently). Barriers included not having time, feeling self-conscious, and fear of injury. Similar barriers and approaches to the measurement of physical activity have been cited in previous research involving college students (Ball et al., 2018; Bray, 2007; Gyurcsik et al., 2004; Sukys et al., 2019). Item responses were summed for total perceived barriers to physical activity.

Benefits of physical activity. Perceived benefits for physical activity refer to potential improvements or gains that will occur through engagement in physical activity (Brown, 2005). Participants responded to a question that asked them to rate how important different factors were in their decision to engage or not engage in physical activity. Potential benefits included, more energy, feeling less stressed, increased confidence, and improved sleep among others. Students responded on a scale from "Not at all important (1)" to "Extremely important (4)". Item responses were summed to create total perceived benefits of physical activity.

Self-efficacy. Self-efficacy, or an individual's confidence in their ability to begin or maintain physical activity was assessed with a single question. Respondents were asked "How sure or confident are you that you can start or continue to exercise for at least 30 minutes per day at least 5 days per week?". They responded using a 4-point Likert type scale of very unsure to very sure. Responses of 1,2 , or 3 were coded as a ' 0 ' for lower self-efficacy and responses of 4 were coded as a ' 1 ' for high self-efficacy for physical activity.

Mode of transportation. Transportation was assessed with a single question. Students were asked "What method of transportation do you use the most to get around town?". Response options included: walk, bike, my car, various forms of public transportation, and other. The other option included space to fill in an unlisted mode of transportation. The response options were dummy coded. Walk and bike were combined to form the 'Active Transportation' group. The "my car" response served as the reference group. 
On-campus residence. A single binary question was used to assess whether the respondent lived on or off-campus.

Greek life affiliation. Membership in a fraternity or sorority was assessed with a single yes or no question.

Gender._Gender was assessed with a single question. Students were asked their gender and to select either "male" or "female".

Class standing. Class standing refers to academic class level. Participants were asked to select their class standing. Options included first year student, sophomore, junior, senior (including $5^{\text {th }}$ year), and graduate or professional.

\section{Data Analysis}

Descriptive statistics, including mean and standard deviation, and bivariate correlations were calculated. Path analysis was used to test the hypothesized model (Figure 1) in SAS v. 9.4 (Cary, NC, 2015). Due to missing data, Full Information Maximum Likelihood (FIML) was used for model estimation. The data set was checked for multicollinearity, outliers, and normality.

Path analysis was chosen to examine the directionality of the relationships between the variables. Root mean square error of approximation (RMSEA), standardized root mean square residual (SRMR), comparative fit index (CFI), and $\chi 2$ were all used to assess model fit. RMSEA values less than .08, SRMR values less than .05, CFI values approaching or exceeding .95, and a nonsignificant $\chi 2$ were used to identify acceptable fit (Hooper et al., 2008; Hu \& Bentler, 1999; Weston \& Gore, 2006). A model with acceptable fit means the proposed model was supported. The model controlled for multiple variables, including membership in a Greek organization, gender, and class standing.

\section{Data Cleaning}


A total of 629 students responded to the study. However, there were 59 respondents who opened the survey and didn't respond to any questions. There were 10 respondents found to be outliers for weekly minutes of physical activity with values greater than 871 minutes $(3$ standard deviations plus the mean). These cases were removed. Analysis were run to check for the assumptions of homoscedasticity, multicollinearity, and normality. Multicollinearity was not present with Tolerance less than 1 (.62 to .85) and VIF values below 10 (1.17 to 1.61).

\section{Results}

Participants were enrolled as full- or part-time students at a midsize mid-Atlantic university. According to university records, the institution the sample was drawn from was $48.96 \%$ female and $80.34 \%$ Caucasian/White. The majority of respondents in the current sample were female $(n=330)$, Caucasian/White $(n=423)$, and lived off-campus $(n=365)$. The participants were distributed across undergraduate (Freshman, Sophomore, Junior, Senior) and graduate class standings. A small percentage of the sample were involved in club $(n=40)$ or intramural sports $(n=52)$. The majority of respondents participated in sports while attending high school for at least one season $(n=405)$. Many students reported free access to a fitness facility in their residence hall or housing complex $(n=295)$. The sample was relatively active as $48.86 \%$ met or exceeded 180 minutes of physical activity per week. On average, respondents lived nearly 14 minutes from the campus recreation center $(M=13.73, S D=9.41)$. Table 1 contains additional sample frequencies.

Descriptive statistics and correlations were calculated for the weekly minutes of physical activity (MVPA; $M=233.75, S D=162.23$ ), perceived barriers (barriers; $M=25.44, S D=6.18$ ), binge drinking behavior (binge; $M=1.84, S D=2.18$ ), and average responses for each achievement goal orientation subscale (task: $M=3.45, S D=.54$; ego: $M=2.24, S D=.77$ ), among other variables. Means and standard deviations are presented in Table 2. Physical activity was positively correlated with binge drinking $(r=.168, p<.01)$, active transport $(r=.123, p=.016)$, self-efficacy 
for physical activity $(r=.368, p<.0001)$ and being male $(r=.149, p<.01)$. Weekly minutes of physical activity was negatively correlated with perceived barriers $(r=-.372, p<.0001)$. Additional correlations are presented in Table 3.

Prior to model testing, the physical activity variable was rescaled in order to reduce difference in scale of standard deviations among the variables and prevent analysis errors (O’Rouke \& Hatcher, 2013). Physical activity values were divided by 100 and the standard deviation was reduced from 162.23 to 1.62 . The initial hypothesized path model, figure 1 , which depicted relationships between achievement goal orientation, perceived barriers, perceived benefits, binge drinking, living on campus, self-efficacy, and primary form of transportation was tested. Car as primary form of transportation was used as a referent category for active and public transportation. Lower self-efficacy was used as the referent group for self-efficacy. Additionally, the effects of gender, membership in a sorority or fraternity, and class standing were controlled for in the model. Female was used as the referent group for gender. The reference group for membership in a sorority or fraternity was not being a member of a fraternity or sorority. The hypothesized model did not have good model fit $\left(\chi^{2}=300.58, \mathrm{df}=43, \chi^{2}\right.$, $p<.0001$, SRMR $=.0789, \mathrm{RMSEA}=.098, \mathrm{CFI}=.685)$. Thus the hypothesized model was not supported.

The next model tested (Figure 2) added covariances between task orientation and ego orientation, task orientation and perceived benefits, ego orientation and Greek life membership, ego orientation and gender, and perceived benefits and gender. This model showed improved fit but still did not meet "good" fit criteria $\left(\chi^{2}=276.55, \mathrm{df}=51, \chi^{2} p<.0001, \mathrm{SRMR}=.075\right.$, RMSEA $=.084, \mathrm{CFI}=.724)$. Through further model development, constraints were placed on covariances and additional paths were drawn based on modification indices. The final model, Figure 3, included a path from public to active transit and dropped several non-meaningful paths. 
This resulted in a more parsimonious model with acceptable fit $\left(\chi^{2}=100.57, \mathrm{df}=54, \chi^{2} p<.0001\right.$, $\mathrm{SRMR}=.050, \mathrm{RMSEA}=.037, \mathrm{CFI}=.943)$. The fit indices for the models can be found in Table 4 . The final model explained $24.51 \%$ of variance in physical activity. Perceived barriers had a negative statistically significant direct effect on physical activity $(\beta=-.252, p<.001)$. High selfefficacy $(\beta=.286, p<.001$; in reference to lower self-efficacy), binge drinking $(\beta=.137, p=$ $.026)$, active transportation $(\beta=.158, p=.002$; in reference to car), and public transportation $(\beta$ $=.105, p=.047$; in reference to car) all had statistically significant positive direct effects on physical activity. Standardized indirect effects can be found in table 5. Perceived barriers, oncampus residence, public transportation, Greek life, and task orientation had statistically significant indirect effects on physical activity.

\section{Discussion}

Although the original model was only partially supported, the present study did find support for a multi-path approach to predicting physical activity. Both environmental and psychological factors were found to have significant effects on physical activity behavior. This finding is consistent with the central theory of social ecologic models (Bronfenbrenner, 1977; Sallis et al., 2008). In the present sample, the effects of individual level factors were stronger in predicting physical activity than the environmental factors. This finding is consistent with previous literature in which interpersonal factors had a larger direct effect on behavior than behavior settings or perceived environment (R. E. Rhodes et al., 2019; Yen \& Li, 2019). Socioecological frameworks propose that interpersonal and environmental factors are interconnected. Thus, the strength of social cognitive factors may be due in part to unobserved environmental factors such as modeled behavior and verbal persuasion (Bandura, 1982; Ickes, McMullen, Pflug, \& Westgate, 2016). The data from the present study can be used to lend support to these assertions. 
Public transportation use had a direct effect on active transportation, and both forms of transportation had direct effects on weekly minutes of physical activity. The positive relationship between active transportation and minutes of physical activity is supported by previous research (Murphy et al., 2019). Living on-campus had a positive effect on the use of active or public transportation. It's possible that, by living on-campus, students had shorter distances to travel and thus were more likely to utilize these forms of transportation. It's also possible that oncampus students had more convenient and regular access to public transportation. For instance, Simons et al. (2014) noted that travel time was a critical factor that influenced young adults' decision to travel by walking or biking. The importance of travel time may, at least partially explain both the negative effect of public transportation use on active transportation, but, positive effect of public transportation on physical activity.

Students in the present sample may have chosen public transportation over active transportation to get to their destination for a few reasons. The built environment for the current sample is generally not very walkable or bike friendly and the public transportation options are relatively consistent and generally accessible. The opportunity to reduce the amount of walking in unfavorable conditions may have also influenced reliance on public transportation. Despite the decision to use public transit, they likely had to rely on walking to get to their bus stop, or to their destination once they exited public transit. Typically, the choice to use public transportation begins and ends with at least a few minutes of walking. This finding adds to the college student literature because most studies have focused exclusively on psychosocial factors and ignored important contextual variables in students' immediate environments (Maselli et al., 2018; R. E. Rhodes et al., 2019).

Researchers have primarily utilized theoretical approaches that focus on the individual such as social cognitive theory, dual-process theories, and self-determination theory (Rhodes et 
al., 2019). While these approaches have shown some effectiveness (Rebar et al., 2016; Teixeira et al., 2012; Young et al., 2014) they fail to incorporate important environmental variables such as transportation (Bauman et al., 2012). The social ecological approach allows for the individual level factors, such as self-efficacy, to be investigated alongside more broad factors like primary mode of transportation. This is important as these findings may be used to inform future interventions. Researchers have found that incorporating multiple factors can lead to successful attempts to change physical activity behavior (Maselli et al., 2018). Thus, examining the role of these important contextual variables may better inform future interventions.

In line with previous literature (Castle et al., 2015; Graupensperger et al., 2018), binge drinking was positively associated with physical activity behavior. Researchers have previously stated that physical activity may increase with alcohol consumption as a way to compensate for unhealthy behavior (Graupensperger et al., 2018). Although this may be true, similar to previous research, affiliation with a fraternity or sorority was found to have a positive direct effect on binge drinking and indirect effect on physical activity via binge drinking (Buscemi et al., 2011). This interactive effect suggests that there may be other cultural norms that can help explain the relationship between binge drinking and physical activity beyond the purging of calories. For instance, social norms, alcohol expectancies, and a lack protective behavioral strategies can all influence alcohol consumption (Barry et al., 2016; N. Rhodes et al., 2019; Tyler et al., 2017). Barry and colleagues (2016) reported members of fraternities and sororities used fewer protective behavioral strategies (i.e. alternating between alcoholic and non-alcoholic beverages) compared students who were not involved with fraternities or sororities. The belief that one should engage in drinking behavior and intent to drink has been positively associated with Greek life (N. Rhodes et al., 2019). If these injunctive norms are influencing identity development, 
membership in a fraternity or sorority may further impact drinking behavior (Thompson \& Romo, 2016).

Individual level factors also impacted engagement in physical activity. For example, selfefficacy had a direct, positive effect on physical activity behavior. Belief in ability has been commonly linked to physical activity behavior (R. E. Rhodes et al., 2019), and this finding is congruent with multiple theories in which self-efficacy, or similar constructs can be found (Bandura, 2004; Hagger \& Chatzisarantis, 2014; Ryan \& Deci, 2017). For instance competence, similar to self-efficacy, describes the need to feel proficient and effectively interact with one's environment (Ryan \& Deci, 2017). Both competence and self-efficacy are positively associated with physical activity behavior across a number of studies, with self-efficacy usually one of the strongest psychosocial predictors of physical activity behavior (Bauman et al., 2012; Chu et al., 2019; Farren et al., 2017; Ng et al., 2012; Shaikh et al., 2018). The strength of self-efficacy as a predictor for physical activity was also highlighted in the present study's findings.

Perceived benefits had a positive direct effect on perceived barriers but not on physical activity. This finding is consistent with previous literature (King et al., 2014; Simons et al., 2014). Simons and colleagues (2014) recommended that some benefits, specifically ecological and health, should not be emphasized when attempting to promote active transportation to young adults. Perceived barriers, however, did have a significant negative effect on physical activity. Perceived barriers have been associated with reduced resistance training (Hurley et al., 2018), vigorous physical activity (King et al., 2014), and overall levels of physical activity (Horacek et al., 2018; Sukys et al., 2019). According to the health belief model, individuals will engage in a behavior based on their perceptions of benefits of, and barriers to, behavior (Tran et al., 2017). It is possible that some of the health benefits of physical activity may not have been salient for the present sample, and thus did not translate into increased intentions to be active. Perceived 
barriers to physical activity may have been more relevant than the perceived benefits of physical activity to the present sample. This could have led to barriers being more salient than perceived benefits. Thus perceived barriers may play a more critical role in determining physical activity engagement in college students.

In contrast to the hypothesized model, there was not a significant effect by either goal orientation subscale on physical activity. However, task orientation did have a significant direct effect on perceived barriers. This indirect effect may help explain why previous researchers have reported an association between high task orientation and perseverance (Kilpatrick et al., 2005). Individuals who focus on self-improvement and mastery may see overcoming barriers as part of the process. For instance, hard work, self-improvement, and overcoming difficulties are features of task orientation. This attitude may facilitate adaptive behaviors such as time management and learning how to exercise and thus directly impact the perceived severity of barriers without directly impacting physical activity itself.

Additionally, the sample was highly active which may have contributed to task and ego goal orientations not having a direct impact on physical activity. For the current sample, physical activity engagement may be more reflective of automatic processes such as implicit attitude or habit. Habits are developed over time as behaviors are repeatedly performed (Gardner, 2015; Lally et al., 2010; Wood \& Neal, 2009). A large portion of the present sample participated in high school sports prior to attending college. These past behaviors may have become routinized and habitual. Rebar and colleagues (2016) suggested that when behaviors become routine, they are regulated by more automatic habitual processes beyond more conscious processes.

The sample was also made up largely of female college students. Female college students typical engage in lower levels of physical activity and consume less alcohol than their male counterparts (Abrantes et al., 2017; Graupensperger et al., 2018; Miller et al., 2008; Stuntz et al., 
2017; Towne et al., 2017). Being a male was positively correlated with physical activity and binge drinking in the present sample. However, gender did not have a significant effect on physical activity in the final model. Despite the highly active sample, it is plausible that the large proportion of female students may have impacted the findings. Researchers have reported that a variety of factors, including alcohol consumption, can influence female college students' physical activity differently compared to males (Davis et al., 2017; Kilpatrick et al., 2005; Shaffer et al., 2017). Thus, a more heterogeneous sample could yield different findings.

In summary, the relationships between variables in the tested models supports the utilization of social ecological frameworks to investigate factors that impact physical activity in college students (Bauman et al., 2012; Sallis, 2018; Sallis et al., 2008). Individual and environmental factors can influence college students' engagement in physical activity. As supported by the literature, self-efficacy can influence level of physical activity in college students (Farren et al., 2017). Broader environmental factors can also influence physical activity behavior (Sallis et al., 2008). The use of a social ecological framework to guide the investigation of factors that influence a more diverse sample of college students' physical activity is needed.

\section{Limitations}

Multiple limitations should be considered when interpreting the results of this study. The participants were university students and were not randomly selected from the campus population. The sample was over representative of female students $(70.77 \%$ of the sample compared to $48.96 \%$ of the institution's population). The recruitment strategy did reach a broad audience and was made accessible to nearly all students, however the sample does not accurately reflect the institutional makeup. This may have impacted the findings of the current study. Furthermore, the current sample was made up of active students. The factors investigated in the current study may have different impacts on the physical activity behaviors of sedentary college 
students and active students. Thus these findings may not be applicable to college students who do not exercise regularly. There is, however, value in understanding how factors impact those who are more active. Similar to how individuals may watch elite athletes in order to improve performance, enhanced understanding of factors associated with increased activity in some students help sedentary students increase their physical activity engagement. The present study also used self-report measures which may be subject to social desirability biases. Both physical activity and alcohol behaviors could be over-reported, or the behaviors in this sample could be unique to those that responded.

\section{Future Directions}

Future studies should aim to include more diverse sample, both in terms of activity level and demographic characteristics. The presented model should be tested in both active and sedentary populations. Comparisons between the models could help researchers further determine similarities and differences between the two samples. A more heterogeneous sample will also allow for researchers to control for factors such as gender. Males tend to have higher levels of physical activity when compared to females and can have different preferences and motives for engaging in physical activity. Further examination of the roles of gender and psychosocial and environmental variables can help advance our understanding of colleges students' physical activity behavior (Davis et al., 2017).

Gathering data from multiple institutions in different regions may help to create a more diverse sample with increased generalizability (Graupensperger et al., 2018). In addition to demographic makeup, data should also be gathered from students across academic disciplines. Researchers have found that academic disciplines can influence health related behaviors (Gathman et al., 2017; Shaikh et al., 2018). More diverse sample populations can help clarify the roles of different factors in determining college students' physical activity behaviors. 
The exact mechanism underlying the positive relationship between alcohol consumption and physical activity in unclear (Davis et al., 2017). Researchers have suggested that college students may engage in physical activity as a way to compensate for consuming alcohol (Davis et al., 2017; Graupensperger et al., 2018). Psychosocial and environmental factors that influence physical activity should be investigated in conjecture with their role in impacting alcohol consumption. For instance, future researchers should investigate how social norms interact with motivation and perceived barriers to impact both alcohol consumption and physical activity in college students (Horacek et al., 2018; N. Rhodes et al., 2019). This may shed light on factors that directly influence behavior or operate indirectly through self-efficacy or decisions to utilize public or active transportation.

Researchers should consider investigating these variables in specific populations where established norms and behaviors may contribute to greater alcohol use, such as fraternities and sororities (Barry et al., 2016; N. Rhodes et al., 2019; Thompson \& Romo, 2016). It may also be worth exploring, in these cases, the potential side-effects of these mechanisms. This could include additional behaviors such as compensatory eating (Abrantes et al., 2017). Researchers can utilize more advanced statistical techniques, beyond correlations, to better explain the underlying relationships between these variables. Techniques such as path analysis and multiple regression may help advance understanding of the relationships between environmental and individual factors and their effects on behavior.

Lastly, the present findings support a social ecologic framework for understanding physical activity in college students. Nevertheless, more objective measures and longitudinal study designs can strengthen our understanding of factors that influence physical activity. Future studies should consider using more objective measurements where available (i.e. accelerometers for physical activity) (Shaikh et al., 2018; Towne et al., 2017). Objective measures of physical 
activity allow for more accurate measurements of frequency, duration, and intensity (Murphy et al., 2019; Towne et al., 2017). . Future researchers should also utilize more longitudinal approaches. This will allow for more investigation into causal relationships among factors associated with physical activity (Towne et al., 2017). These findings can enhance our understanding of the relationship between individual and environmental factors.

\section{Application}

The use of more longitudinal approaches can be used to examine the relationship between environmental changes, psychosocial factors, and behavior. For instance, researchers may investigate the relationship of different environmental factors such as availability of various forms of transportation, neighborhood walkability, and individual factors such as self-efficacy, perceived barriers, and motivation across time. These findings may be particularly useful if data collection occurs before and after campus development changes that impact students' ability to use active or public transportation.

Interventions may be designed to target specific predictors of physical activity behavior in college students. College wellness programs, administrators, and recreation and student-life coordinators may seek to identify which factors associated with physical activity can be modified. Furthermore, they may attempt to find intervention approaches that can help increase or maintain physical activity while decreasing unhealthy behaviors, such as binge drinking.

Institutions may want to target various barriers faced by college students in order to help facilitate their engagement in physical activity. Barriers at the environmental, policy, and individual or interpersonal levels of the social ecological model can be addressed. For instance, colleges and universities could enact policies that require students to enroll in mandatory physical education (PE) or lifetime activity classes. This could help reduce some of the barriers students commonly report such as not having someone to exercise with and a lack of knowledge 
about how to exercise. Furthermore, these PE courses may help students develop more selfefficacy in the ability to become active through vicarious and personal experiences.

Another policy change that may increase activity is to limit the number of cars on campus. Active students may be more active because of an increased reliance on active (such as biking or walking) and public transportation over the use of cars. Moving parking to the edge of campus would likely require students to utilize active transportation to get to more central locations on campus. Symbolically this may also serve to alter the norms of transportation on campus as cars would be restricted to the outer edge. Active transportation would then become a regular behavior by while on campus, while driving would be limited to off campus activities. Colleges and universities can also leverage school pride and identity to challenge sedentary norms by seeking to establish a culture in which students choose opportunities to be active over sedentary activities.

Other barriers reported by college students are not having a safe place to be active and/or a lack of time. Institutions can alter the built environment to improve safety for active transportation by increasing the number of sidewalks, adding street lights, safety patrols, and/or safety call boxes to existing and new sidewalk. The current institution has multiple campuses. Adding campus recreation centers on each campus will increase access and convenience for students. In addition to providing more gym space, institutions can provide additional well-lit recreation fields and basketball or tennis courts to provide accessible alternatives for those that aren't on main campus. This would increase the number of safe spaces and potentially reduce transportation time.

A reduction in all, or even some, of the aforementioned barriers could make engaging in physical activity a more desirable and less costly behavior, thus increasing physical activity levels across the student body. Stakeholders should take these changes, and others, into 
consideration in future attempts to improve levels of physical activity on college campuses.

These changes should include larger environmental and policy adjustments, as well as, target individual level factors. The application of social ecological models can facilitate these efforts. 


\section{References}

Abrantes, A. M., Scalco, M. D., O’Donnell, S., Minami, H., \& Read, J. P. (2017). Drinking and exercise behaviors among college students: Between and within-person associations. Journal of Behavioral Medicine, 40(6), 964-977. https://doi.org/10.1007/s10865-0179863-X

Allen, R., \& Ross, C. M. (2013). An assessment of proximity of fitness facilities and equipment and actual perceived usage by undergraduate university students: A pilot study. Recreational Sports Journal, 37(2), 123-135. https://doi.org/10.1123/rsj.37.2.123

American College Health Association. (2014). American College Health Association-National College Health Assessment II: ACHA-NCHA II Sample Survey.

American College Health Association. (2019). American College Health Association-National College Health Assessment II: Undergraduate Student Executive Summary Spring 2019. American College Health Association.

Arterberry, B. J., Smith, A. E., Martens, M. P., Cadigan, J. M., \& Murphy, J. G. (2014). Protective behavioral strategies, social norms, and alcohol-related outcomes. Addiction Research \& Theory, 22(4), 279-285. https://doi.org/10.3109/16066359.2013.838226

Ball, J. W., Bice, M. R., \& Maljak, K. A. (2018). Exploring the Relationship Between College Students' Barriers to Exercise and Motivation. American Journal of Health Studies, $33(2), 61-69$.

Bandura, A. (1982). Self-efficacy mechanism in human agency. American Psychologist, 37(2).

Bandura, A. (2004). Health promotion by social cognitive means. Health Education \& Behavior: The Official Publication of the Society for Public Health Education, 31(2), 143-164. https://doi.org/10.1177/1090198104263660 
Barry, A., Madson, M., Moorer, K., \& Christman, K. (2016). Predicting Use of Protective Behavioral Strategies: Does Fraternity/Sorority Affiliation Matter? Journal of Student Affairs Research and Practice, 53(3), 294-304. https://doi.org/10.1080/19496591.2016.1165107

Bauman, A. E., Reis, R. S., Sallis, J. F., Wells, J. C., Loos, R. J., Martin, B. W., \& Lancet Physical Activity Series Working Group. (2012). Correlates of physical activity: Why are some people physically active and others not? The Lancet, 380(9838), 258-271.

Biddle, S., Wang, C. K. J., Kavussanu, M., \& Spray, C. (2003). Correlates of achievement goal orientations in physical activity: A systematic review of research. European Journal of Sport Science, 3(5), 1-20. https://doi.org/10.1080/17461390300073504

Bray, S. R. (2007). Self-Efficacy for Coping With Barriers Helps Students Stay Physically Active During Transition to Their First Year at a University. Research Quarterly for Exercise and Sport, 78(2), 61-70. https://doi.org/10.1080/02701367.2007.10599404

Bronfenbrenner, U. (1977). Toward an experimental ecology of human development. American Psychologist, 32(7), 513-531. https://doi.org/10.1037/0003-066X.32.7.513

Buscemi, J., Martens, M. P., Murphy, J. G., Yurasek, A. M., \& Smith, A. E. (2011). Moderators of the Relationship Between Physical Activity and Alcohol Consumption in College Students. Journal of American College Health, 59(6), 503-509. https://doi.org/10.1080/07448481.2010.518326

Castle, J., Alman II, R., Kostelnik, R., \& Smith, S. (2015). Factors that affect the usage of fitness and recreation centers by students on college campuses. Journal of Physical Education and Sports Management, 2(2). https://doi.org/10.15640/jpesm.v2n2a8

Chu, T. L., Zhang, T., \& Li, H. (2019). Roles of Physical Activity Type in Exercise Motivational Profiles and Behavioral Frequencies Among College Freshmen. 13. 
Davis, H. A., Riley, E. N., Smith, G. T., Milich, R., \& Burris, J. L. (2017). Alcohol use and strenuous physical activity in college students: A longitudinal test of 2 explanatory models of health behavior. Journal of American College Health, 65(2), 112-121. https://doi.org/10.1080/07448481.2016.1260571

Duda, J. L. (1989). Relationship between task and ego orientation and the perceived purpose of sport among high school athletes. Journal of Sport and Exercise Psychology, 11(3), 318335. https://doi.org/10.1123/jsep.11.3.318

Duda, J. L., \& Nicholls, J. G. (1992). Dimensions of achievement motivation in schoolwork and sport. Journal of Educational Psychology, 84(3), 290-299. https://doi.org/10.1037/00220663.84.3.290

Farren, G. L., Zhang, T., Martin, S. B., \& Thomas, K. T. (2017). Factors related to meeting physical activity guidelines in active college students: A social cognitive perspective. Journal of American College Health, 65(1), 10-21. https://doi.org/10.1080/07448481.2016.1229320

Gardner, B. (2015). A review and analysis of the use of 'habit' in understanding, predicting and influencing health-related behaviour. Health Psychology Review, 9(3), 277-295. https://doi.org/10.1080/17437199.2013.876238

Gathman, P. C., Grabowski, N. R., Carr, J. W., \& Todd, M. K. (2017). Campus Recreation Use and Health Behaviors among College Students in Different Academic Disciplines. Recreational Sports Journal, 41(1), 87-99. https://doi.org/10.1123/rsj.2016-0011

Graupensperger, S., Wilson, O., Bopp, M., \& Blair Evans, M. (2018). Longitudinal association between alcohol use and physical activity in US college students: Evidence for directionality. Journal of American College Health, 1-8. https://doi.org/10.1080/07448481.2018.1536058 
Grubbs, L., \& Carter, J. (2002). The Relationship of Perceived Benefits and Barriers to Reported Exercise Behaviors in College Undergraduates: Family \& Community Health, 25(2), 7684. https://doi.org/10.1097/00003727-200207000-00009

Guthold, R., Stevens, G. A., Riley, L. M., \& Bull, F. C. (2018). Worldwide trends in insufficient physical activity from 2001 to 2016: A pooled analysis of 358 population-based surveys with 1.9 million participants. The Lancet Global Health, 6(10), e1077-e1086. https://doi.org/10.1016/S2214-109X(18)30357-7

Gyurcsik, N. C., Bray, S. R., \& Brittain, D. R. (2004). Coping with barriers to vigorous physical activity during transition to university. Family \& Community Health, 27(2), 130-142.

Hagger, M. S., \& Chatzisarantis, N. L. D. (2014). An Integrated Behavior Change Model for Physical Activity. Exercise and Sport Sciences Reviews, 42(2), 62-69. https://doi.org/10.1249/JES.0000000000000008

Hingson, R. (2017). Magnitude and Trends in Heavy Episodic Drinking, Alcohol-Impaired Driving, and Alcohol-Related Mortality and Overdose Hospitalizations Among Emerging Adults of College Ages 18-24 in the United States, 1998-2014. JOURNAL OF STUDIES ON ALCOHOL AND DRUGS, 9.

Hooper, D., Coughlan, J., \& Mullen, M. (2008). Structural equation modelling: Guidelines for determining model fit. The Electronic Journal of Buisness Research Methods, 6, 53-60.

Horacek, T. M., Dede Yildirim, E., Kattelmann, K., Brown, O., Byrd-Bredbenner, C., Colby, S., Greene, G., Hoerr, S., Kidd, T., Koenings, M. M., Morrell, J., Olfert, M. D., Phillips, B., Shelnutt, K., \& White, A. (2018). Path Analysis of Campus Walkability/Bikeability and College Students' Physical Activity Attitudes, Behaviors, and Body Mass Index. American Journal of Health Promotion, 32(3), 578-586. https://doi.org/10.1177/0890117116666357 
Hu, L., \& Bentler, P. M. (1999). Cutoff criteria for fit indexes in covariance structure analysis: Conventional criteria versus new alternatives. Structural Equation Modeling: A Multidisciplinary Journal, 6(1), 1-55. https://doi.org/10.1080/10705519909540118

Hurley, K. S., Flippin, K. J., Blom, L. C., Hoover, D. L., \& Judge, L. W. (2018). Practices, Perceived Benefits, and Barriers to Resistance Training Among Women Enrolled in College. 14.

Ickes, M. J., McMullen, J., Pflug, C., \& Westgate, P. M. (2016). Impact of a University-based Program on Obese College Students' Physical Activity Behaviors, Attitudes, and Selfefficacy. American Journal of Health Education, 47(1), 47-55. https://doi.org/10.1080/19325037.2015.1111178

Kilpatrick, M., Bartholomew, J., \& Reimer, H. (2003). The measurement of goal orientations in exercise. Journal of Sport Behavior, 26, 121-136.

Kilpatrick, M., Hebert, E., \& Bartholomew, J. (2005). College Students' Motivation for Physical Activity: Differentiating Men’s and Women's Motives for Sport Participation and Exercise. Journal of American College Health, 54(2), 87-94.

King, K., Vidourek, R., English, L., \& Merianos, A. (2014). Vigorous physical activity among college students: Using the health belief model to assess involvement and social support. 14.

Kuperberg, A., \& Padgett, J. E. (2017). Partner Meeting Contexts and Risky Behavior in College Students' Other-Sex and Same-Sex Hookups. The Journal of Sex Research, 54(1), 55-72. https://doi.org/10.1080/00224499.2015.1124378

Kyu, H. H., Bachman, V. F., Alexander, L. T., Mumford, J. E., Afshin, A., Estep, K., Veerman, J. L., Delwiche, K., Iannarone, M. L., Moyer, M. L., Cercy, K., Vos, T., Murray, C. J. L., \& Forouzanfar, M. H. (2016). Physical activity and risk of breast cancer, colon cancer, 
diabetes, ischemic heart disease, and ischemic stroke events: Systematic review and doseresponse meta-analysis for the Global Burden of Disease Study 2013. BMJ, i3857. https://doi.org/10.1136/bmj.i3857

Lally, P., van Jaarsveld, C. H. M., Potts, H. W. W., \& Wardle, J. (2010). How are habits formed: Modelling habit formation in the real world. European Journal of Social Psychology, 40(6), 998-1009. https://doi.org/10.1002/ejsp.674

Lee, I.-M., Sesso, H. D., Oguma, Y., \& Paffenbarger, R. S., Jr. (2003). Relative intensity of physical activity and risk of coronary heart disease. Circulation, 107(8), 1110-1116. https://doi.org/10.1161/01.CIR.0000052626.63602.58

Lee, I.-M., Shiroma, E. J., Lobelo, F., Puska, P., Blair, S. N., Katzmarzyk, P. T., \& Lancet Physical Activity Series Working Group. (2012). Effect of physical inactivity on major non-communicable diseases worldwide: An analysis of burden of disease and life expectancy. The Lancet, 380(9838), 219-229.

Maselli, M., Ward, P. B., Gobbi, E., \& Carraro, A. (2018). Promoting physical activity among university students: A systematic review of controlled trials. American Journal of Health Promotion, 32(7), 1602-1612. https://doi.org/10.1177/0890117117753798

Miller, K. H., Noland, M., Rayens, M. K., \& Staten, R. (2008). Characteristics of users and nonusers of a campus recreation center. Recreational Sports Journal, 32(2), 87-96. https://doi.org/10.1123/rsj.32.2.87

Murphy, J. J., MacDonncha, C., Murphy, M. H., Murphy, N., Nevill, A. M., \& Woods, C. B. (2019). What psychosocial factors determine the physical activity patterns of university students? Journal of Physical Activity and Health, 16(5), 325-332. https://doi.org/10.1123/jpah.2018-0205 
National Institude on Alcohol Abuse and Alcoholism. (2017). Drinking Levels Defined. https://www.niaaa.nih.gov/alcohol-health/overview-alcohol-consumption/moderatebinge-drinking.

Ng, J. Y. Y., Ntoumanis, N., Thøgersen-Ntoumani, C., Deci, E. L., Ryan, R. M., Duda, J. L., \& Williams, G. C. (2012). Self-Determination Theory Applied to Health Contexts: A MetaAnalysis. Perspectives on Psychological Science, 7(4), 325-340. https://doi.org/10.1177/1745691612447309

Nicholls, J. G. (1989). The competitive ethos and democratic education. Harvard University Press.

Nogueira, D., Faerstein, E., Rugani, I., Chor, D., Lopes, C. S., \& Werneck, G. L. (2009). Does leisure-time physical activity in early adulthood predict later physical activity? Pro-Saude Study. Revista Brasileira de Epidemiologia, 12(1), 3-9. https://doi.org/10.1590/S1415$790 \times 2009000100001$

Pintrich, P. R. (2000). An achievement goal theory perspective on issues in motivation terminology, theory, and research. Contemporary Educational Psychology, 25(1), 92104. https://doi.org/10.1006/ceps.1999.1017

Pratt, M., Perez, L. G., Goenka, S., Brownson, R. C., Bauman, A., Sarmiento, O. L., \& Hallal, P. C. (2015). Can population levels of physical activity be increased? Global evidence and experience. Progress in Cardiovascular Diseases, 57(4), 356-367.

Rebar, A. L., Dimmock, J. A., Jackson, B., Rhodes, R. E., Kates, A., Starling, J., \& Vandelanotte, C. (2016). A systematic review of the effects of non-conscious regulatory processes in physical activity. Health Psychology Review, 10(4), 395-407. https://doi.org/10.1080/17437199.2016.1183505 
Reed, J. A., \& Phillips, D. A. (2005). Relationships between physical activity and the proximity of exercise facilities and home exercise equipment used by undergraduate university students. Journal of American College Health, 53(6), 285-290. https://doi.org/10.3200/JACH.53.6.285-290

Rhodes, N., Potocki, B., \& Thomas, S. (2019). Predicting College Student Drinking and Smoking Intentions With Cognitively Accessible Attitudes and Norms. Health Education \& Behavior, 46(2), 267-274. https://doi.org/10.1177/1090198118818238

Rhodes, R. E., Janssen, I., Bredin, S. S. D., Warburton, D. E. R., \& Bauman, A. (2017). Physical activity: Health impact, prevalence, correlates and interventions. Psychology \& Health, 32(8), 942-975. https://doi.org/10.1080/08870446.2017.1325486

Rhodes, R. E., McEwan, D., \& Rebar, A. L. (2019). Theories of physical activity behaviour change: A history and synthesis of approaches. Psychology of Sport and Exercise, 42, 100-109. https://doi.org/10.1016/j.psychsport.2018.11.010

Rinker, D. V., Diamond, P. M., Walters, S. T., Wyatt, T. M., \& DeJong, W. (2016). Distinct Classes of Negative Alcohol-Related Consequences in a National Sample of Incoming First-Year College Students: A Latent Class Analysis. Alcohol and Alcoholism, 51(5), 7.

Roberts, G. C., Treasure, D. C., \& Balague, G. (1998). Achievement goals in sport: The development and validation of the Perception of Success Questionnaire. Journal of Sports Sciences, 16(4), 337-347. https://doi.org/10.1080/02640419808559362

Ryan, R. M., \& Deci, E. L. (2017). Self-determination theory: Basic psychological needs in motivation, development, and wellness. Guilford Press.

Sallis, J. F. (2018). Needs and challenges related to multilevel interventions: Physical activity examples. Health Education \& Behavior, 45(5), 661-667. https://doi.org/10.1177/1090198118796458 
Sallis, J. F., Bull, F., Guthold, R., Heath, G. W., Inoue, S., Kelly, P., Oyeyemi, A. L., Perez, L. G., Richards, J., \& Hallal, P. C. (2016). Progress in physical activity over the Olympic quadrennium. The Lancet, 388(10051), 1325-1336. https://doi.org/10.1016/S0140$6736(16) 30581-5$

Sallis, J. F., Cervero, R. B., Ascher, W., Henderson, K. A., Kraft, M. K., \& Kerr, J. (2006). An ecological approach to creating active living communities. Annual Review of Public Health, 27(1), 297-322. https://doi.org/10.1146/annurev.publhealth.27.021405.102100

Sallis, J. F., Owen, N., \& Fisher, E. B. (2008). Ecological models of health behavior. In K. Glanz, B. K. Rimer, \& K. Viswanath (Eds.), Health behavior and health education: Theory, research, and practice (pp. 465-485). Jossey-Bass.

Schwartz, J., Rhodes, R., Bredin, S., Oh, P., \& Warburton, D. (2019). Effectiveness of Approaches to Increase Physical Activity Behavior to Prevent Chronic Disease in Adults: A Brief Commentary. Journal of Clinical Medicine, 8(3), 295. https://doi.org/10.3390/jcm8030295

Shaffer, K., Bopp, M., Papalia, Z., Sims, D., \& Bopp, C. M. (2017). The Relationship of Living Environment with Behavioral and Fitness Outcomes by Sex: An Exploratory Study in College-aged Students. 11.

Shaikh, H. M., Patterson, M. S., Lanning, B., Umstattd Meyer, M. R., \& Patterson, C. A. (2018). Assessing college students' use of campus recreation facilities through individual and environmental factors. Recreational Sports Journal, 42(2), 145-159. https://doi.org/10.1123/rsj.2017-0033

Simons, D., Clarys, P., De Bourdeaudhuij, I., de Geus, B., Vandelanotte, C., \& Deforche, B. (2014). Why do young adults choose different transport modes? A focus group study. Transport Policy, 36, 151-159. https://doi.org/10.1016/j.tranpol.2014.08.009 
Soedamah-Muthu, S. S., De Neve, M., Shelton, N. J., Tielemans, S. M. A. J., \& Stamatakis, E. (2013). Joint associations of alcohol consumption and physical activity with all-cause and cardiovascular mortality. The American Journal of Cardiology, 112(3), 380-386. https://doi.org/10.1016/j.amjcard.2013.03.040

Spence, J. C., \& Lee, R. E. (2003). Toward a comprehensive model of physical activity. Psychology of Sport and Exercise, 4(1), 7-24. https://doi.org/10.1016/S14690292(02)00014-6

Staten, R. R., Miller, K., Noland, M. P., \& Rayens, M. K. (2005). College students' physical activity: Application of an ecological perspective. American Journal of Health Studies, 20(1), 58-65.

Stuntz, C. P., Smith, C., \& Vensel, K. (2017). Is the relationship between lifestyle factors and physical activity mediated by psychological needs and motivation? International Journal of Sport and Exercise Psychology, 15(3), 291-305. https://doi.org/10.1080/1612197X.2015.1079923

Sukys, S., Cesnaitiene, V. J., Emeljanovas, A., Mieziene, B., Valantine, I., \& Ossowski, Z. M. (2019). Reasons and Barriers for University Students' Leisure-Time Physical Activity: Moderating Effect of Health Education. Perceptual and Motor Skills, 126(6), 1084-1100. https://doi.org/10.1177/0031512519869089

Teixeira, P. J., Carraça, E. V., Markland, D., Silva, M. N., \& Ryan, R. M. (2012). Exercise, physical activity, and self-determination theory: A systematic review. The International Journal of Behavioral Nutrition and Physical Activity, 9(Journal Article). https://doi.org/10.1186/1479-5868-9-78 
Thompson, C. M., \& Romo, L. K. (2016). College Students' Drinking and Posting About Alcohol: Forwarding a Model of Motivations, Behaviors, and Consequences. Journal of Health Communication, 21(6), 688-695. https://doi.org/10.1080/10810730.2016.1153763

Towne, S. D., Ory, M. G., Smith, M. L., Peres, S. C., Pickens, A. W., Mehta, R. K., \& Benden, M. (2017). Accessing physical activity among young adults attending a university: The role of sex, race/ethnicity, technology use, and sleep. BMC Public Health, 17(1), 721. https://doi.org/10.1186/s12889-017-4757-y

Tran, D.-M. T., Zimmerman, L. M., Kupzyk, K. A., Shurmur, S. W., Pullen, C. H., \& Yates, B. C. (2017). Cardiovascular risk factors among college students: Knowledge, perception, and risk assessment. Journal of American College Health, 65(3), 158-167. https://doi.org/10.1080/07448481.2016.1266638

Tyler, K. A., Schmitz, R. M., Adams, S. A., \& Simons, L. G. (2017). Social factors, alcohol expectancy, and drinking behavior: A comparison of two college campuses. Journal of Substance Use, 22(4), 357-364. https://doi.org/10.1080/14659891.2016.1223762

Warburton, D. E., Nicol, C. W., \& Bredin, S. S. (2006). Health benefits of physical activity: The evidence. CMAJ: Canadian Medical Association Journal, 174(6), 801-809. https://doi.org/10.1503/cmaj.051351

Watson, J. C., Ayers, S. F., Zizzi, S., \& Naoi, A. (2006). Student recreation centers: A comparison of users and non-users on psychosocial variables. Recreational Sports Journal, 30(1), 9-19. https://doi.org/10.1123/rsj.30.1.9

Weitzman, E., Nelson, T., \& Wechsler, H. (2003). Taking up binge drinking in college: The influences of person, social group, and environment. Journal of Adolescent Health, 32(1), 26-35. https://doi.org/10.1016/S1054-139X(02)00457-3 
Weston, R., \& Gore, P. A. (2006). A Brief Guide to Structural Equation Modeling. The Counseling Psychologist, 34(5), 719-751. https://doi.org/10.1177/0011000006286345

Wood, W., \& Neal, D. T. (2009). The habitual consumer. Journal of Consumer Psychology, 19(4), 579-592. https://doi.org/10.1016/j.jcps.2009.08.003

World Health Organization. (2018). Noncommunicable diseases country profiles 2018. World Health Organization.

Yen, H.-Y., \& Li, C. (2019). Determinants of physical activity: A path model based on an ecological model of active living. PLOS ONE, 14(7), e0220314. https://doi.org/10.1371/journal.pone.0220314

Yoon, A., Kim, K., \& Lee, S. (2014). The effects of residence on the eating and exercise habits of college freshmen in US. International Journal of Applied Sports Sciences, 26(1), 1-10. https://doi.org/10.24985/ijass.2014.26.1.1

Young, M. D., Plotnikoff, R. C., Collins, C. E., Callister, R., \& Morgan, P. J. (2014). Social cognitive theory and physical activity: A systematic review and meta-analysis. Obesity Reviews, 15(12), 983-995. https://doi.org/10.1111/obr.12225

Zizzi, S., Ayers, S. F., Watson, J. C., \& Keeler, L. (2004). Assessing the impact of new student campus recreation centers. Journal of Student Affairs Research and Practice, 41(4). https://doi.org/10.2202/1949-6605.1390

Zizzi, S., Keeler, L., \& Watson II, J. C. (2006). The interaction of goal orientation and stage of change on exercise behavior in college students. Journal of Sport Behavior, 29(1), 16. 
Table 1 - Sample Characteristics

Table 1

Study Sample Characteristics

Institutional

Variable $n \quad$ Percentage Percentage

Gender

Male

145

29.77

51.04

Female

342

70.23

48.96

Ethnicity

Caucasian/White

African-American

Hispanic-American

Asian-American

International Student

Other

Residence

On-Campus

Off-Campus

Class

Freshman

Sophomore

Junior

Senior
423

15

7

7

21

7

88.13

3.13

4.27

1.46

3.18

1.46

1.77

4.38

6.28

1.46

4.15
195

365

34.82

65.18

102

21.56

99

20.93

56

11.84

129

27.27 
Fulltime Student

Yes

No

Member of Sorority/Fraternity

Yes

No
106

548

21

454
18.93

3.69

96.31

81.07

Note: Institutional data was obtained from an Integrated Postsecondary Education Data System (IPEDS) report. The report was retrieved from the institution's website. Data was not available for residence, detailed class breakdown, fulltime vs part-time enrollment, or Greek life affiliation. 
A MODEL OF PHYSICAL ACTIVITY

Table 2

Table 2 - Descriptive Statistics

Descriptive Statistics

\begin{tabular}{|c|c|c|c|c|c|c|}
\hline Variable & $n$ & Percentage & & & & \\
\hline \multicolumn{7}{|l|}{ Transportation } \\
\hline Walk & 187 & 34.89 & & & & \\
\hline Bike & 5 & .93 & & & & \\
\hline Car & 199 & 37.13 & & & & \\
\hline Public Transit & 108 & 20.15 & & & & \\
\hline Other & 37 & 6.9 & & & & \\
\hline \multicolumn{7}{|l|}{ Self-Efficacy } \\
\hline Very unsure & 38 & 7.51 & & & & \\
\hline Somewhat & 106 & 20.95 & & & & \\
\hline \multicolumn{7}{|l|}{ unsure } \\
\hline Somewhat sure & 175 & 34.58 & & & & \\
\hline Very sure & 187 & 36.96 & & & & \\
\hline Variable & $n$ & Mean & Median & SD & Skewness & Kurtosis \\
\hline Binge & 369 & 1.84 & 1 & 2.18 & 1.48 & 2.46 \\
\hline Physical Activity & 386 & 233.75 & 180.00 & 162.23 & 1.17 & 1.31 \\
\hline Perceived Barriers & 394 & 25.44 & 25.00 & 6.18 & -.242 & -.249 \\
\hline Perceived Benefits & 378 & 19.59 & 20.00 & 3.71 & -.986 & .975 \\
\hline Ego Orientation & 292 & 2.24 & 2.20 & .77 & .318 & -.466 \\
\hline
\end{tabular}

Avg. 
A MODEL OF PHYSICAL ACTIVITY

Task Orientation

292

3.45

3.50

.54

$-.840$

.715

Avg.

$n=$ number of item responses 


\section{Table 3 - Correlations}

Table 3

Correlations

\begin{tabular}{|c|c|c|c|c|c|c|c|c|c|c|c|c|}
\hline Measure & 1 & 2 & 3 & 4 & 5 & 6 & 7 & 8 & 9 & 10 & 11 & 12 \\
\hline 1. PA & - & & & & & & & & & & & \\
\hline 2. Barriers & $-.372 * *$ & - & & & & & & & & & & \\
\hline 3. Benefits & .082 & .082 & - & & & & & & & & & \\
\hline 4. Binge & $.168 *$ & .087 & .027 & - & & & & & & & & \\
\hline 5. Active & $.123 *$ & -.011 & -.030 & $0.147^{*}$ & - & & & & & & & \\
\hline 6. Public & .026 & -.038 & .006 & -0.038 & $-.377 * *$ & - & & & & & & \\
\hline 7. On-Campus & -.024 & .004 & -.017 & $0.140^{*}$ & $.254 * *$ & $.236 * *$ & - & & & & & \\
\hline 8. Ego & $.141 *$ & -.015 & .002 & $0.156^{*}$ & .026 & $.124^{*}$ & .055 & - & & & & \\
\hline 9. Task & .078 & $-.159 *$ & $.314 * *$ & -0.092 & .066 & .042 & .014 & $.225^{*}$ & - & & & \\
\hline 10. Self-Efficacy & $.368^{* *}$ & $-.425 * *$ & $.234 * *$ & 0.077 & .009 & .005 & .015 & $.157 *$ & $.227^{* *}$ & - & & \\
\hline 11. Greek & -.029 & -.005 & -.032 & $0.417 * *$ & $.147 *$ & -.025 & $.174 * *$ & $.131 *$ & .016 & $-.088 *$ & - & \\
\hline 12. Gender & $.149 *$ & $-.191 *$ & $-.138 *$ & $0.343 * *$ & .041 & .068 & -.010 & $.223 *$ & .021 & $.108 *$ & .086 & - \\
\hline 13. Class & -.022 & .059 & .024 & 0.0194 & $-.201 * *$ & $-.174 *$ & $-.533 * *$ & .020 & -.057 & .011 & -.107 & .014 \\
\hline
\end{tabular}


$* p<.05$

$* * p<.0001$ 
Table 4

Table 4 - Fit Indices

Goodness-of-Fit Indices

\begin{tabular}{lcccccccc}
\hline \multicolumn{1}{c}{ Model } & $\mathrm{X}^{2}$ & $\mathrm{df}$ & $\Delta \mathrm{X}^{2}$ & $\Delta \mathrm{df}$ & $\mathrm{CFI}$ & SRMR & RMSEA & (RMSEA CL90) \\
\hline Baseline Model & 895.89 & 78 & & & & & & \\
Hypothesized & 300.58 & 43 & 595.31 & 35 & .69 & .079 & .098 & $(.087-.108)$ \\
Rev. Model 1 & 276.55 & 51 & 24.03 & 8 & .72 & .075 & .084 & $(.074-.094)$ \\
Final Model & 100.57 & 54 & 175.98 & 3 & .94 & .050 & .037 & $(.026-.048)$
\end{tabular}

Note: $\mathrm{X}^{2}=$ chi-square; $\mathrm{df}=$ degrees of freedom; $\mathrm{CFI}=$ Comparative Fit Index; SRMR = Standardized Root Mean Square Residual; RMSEA = Root Mean Square Error of Approximation; RMSEA CL $90=$ RMSEA 90\% Confidence Limits. 
Table 5 - Indirect Effects

Table 5

Standardized Indirect Effects

\begin{tabular}{|c|c|c|c|c|c|c|c|}
\hline & Barriers & Residence & Public & Benefits & Class & Greek & Task \\
\hline Active & & $-0.129 * *$ & & & $-0.130 * *$ & $0.032^{* *}$ & \\
\hline PA & $-0.111 * *$ & $0.067 * *$ & $-0.076 * *$ & -0.002 & 0.013 & $0.050^{*}$ & $0.078^{* *}$ \\
\hline Public & & & & & $-0.141 * *$ & $0.035^{* *}$ & \\
\hline SE & & & & $-0.070 * *$ & & & $0.084 * *$ \\
\hline \multicolumn{8}{|c|}{ Note: Barriers=Perceived Barriers; Residence=On-Campus Residence (Reference Off-Campus } \\
\hline \multicolumn{8}{|c|}{ Residence); Benefits=Perceived Benefits; Greek=Member of Fraternity/Sorority (Reference } \\
\hline \multicolumn{8}{|c|}{ not a member of a Fraternity/Sorority); Task=Task Orientation; Active=Active Transportation } \\
\hline \multicolumn{8}{|c|}{ (Reference Car); PA=Physical Activity; SE=Self-efficacy (Reference Lower Self-efficacy) } \\
\hline \multicolumn{8}{|l|}{$*_{p}<.05$} \\
\hline$* *$ & & & & & & & \\
\hline
\end{tabular}


Figure 1 - Hypothesized Model

Figure 1

Model 1 - Hypothesized Model

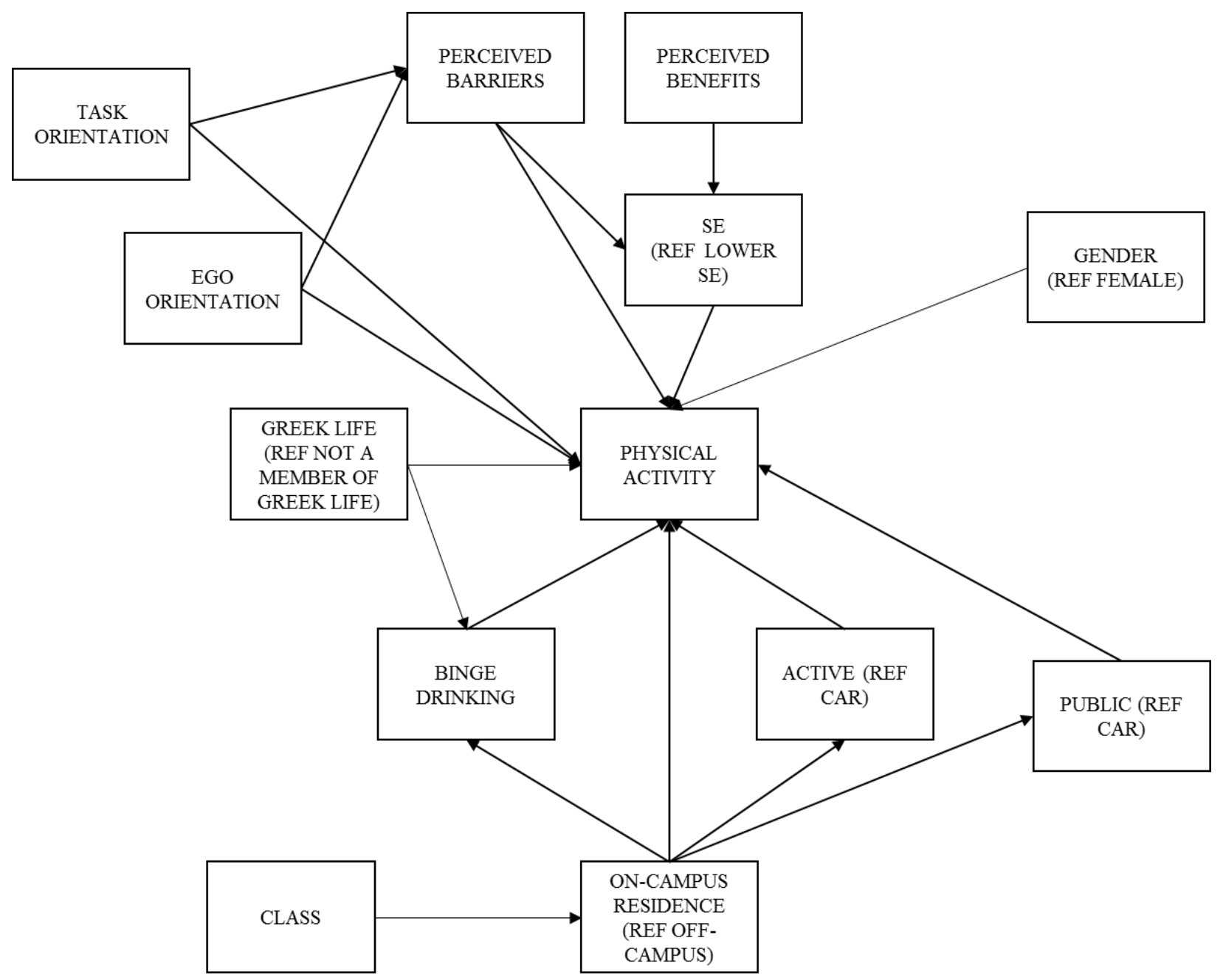

Note: SE (Ref Lower SE) = Self-Efficacy (Reference group Lower Self-Efficacy); Greek Life $($ Ref not a member of Greek Life $)=$ Member of a Fraternity/Sorority (Reference group not a member of a Fraternity/Sorority); Active $($ Ref Car) $=$ Active Transportation (Reference group Car); Public $($ Ref Car) $=$ Public Transportation (Reference group Car).

$*_{p} p<.05$

$* * p<.01$ 
Figure 2 - SAS Revised Model

Figure 2

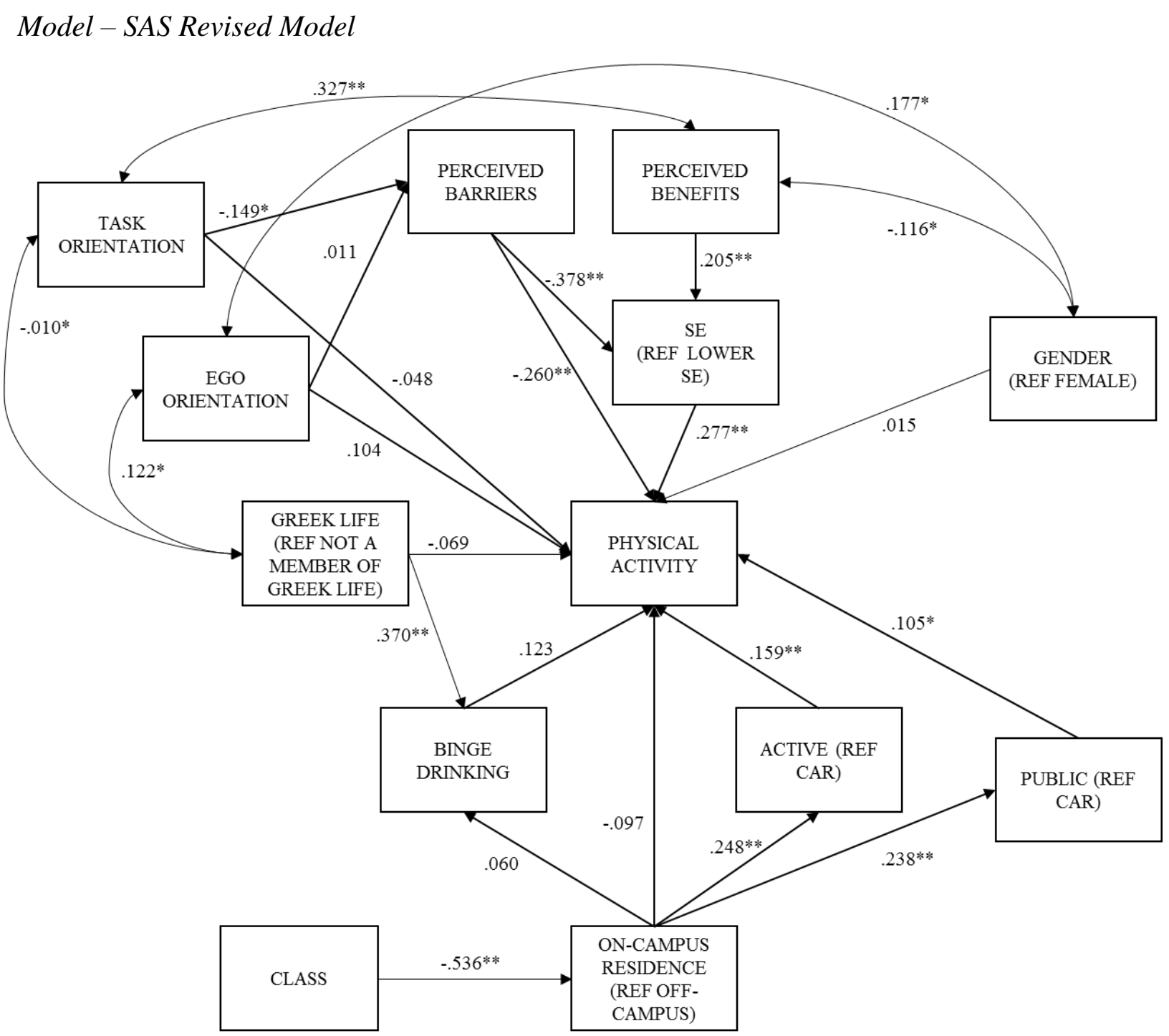

Note: SE (Ref Lower SE) = Self-Efficacy (Reference group Lower Self-Efficacy); Greek Life $($ Ref not a member of Greek Life $)=$ Member of a Fraternity/Sorority (Reference group not a member of a Fraternity/Sorority); Active (Ref Car) = Active Transportation (Reference group Car); Public $($ Ref Car $)=$ Public Transportation (Reference group Car).

$* p<.05$

$* * p<.01$ 
Figure 3 - Final Model

Figure 3

Model 3 - Final Model

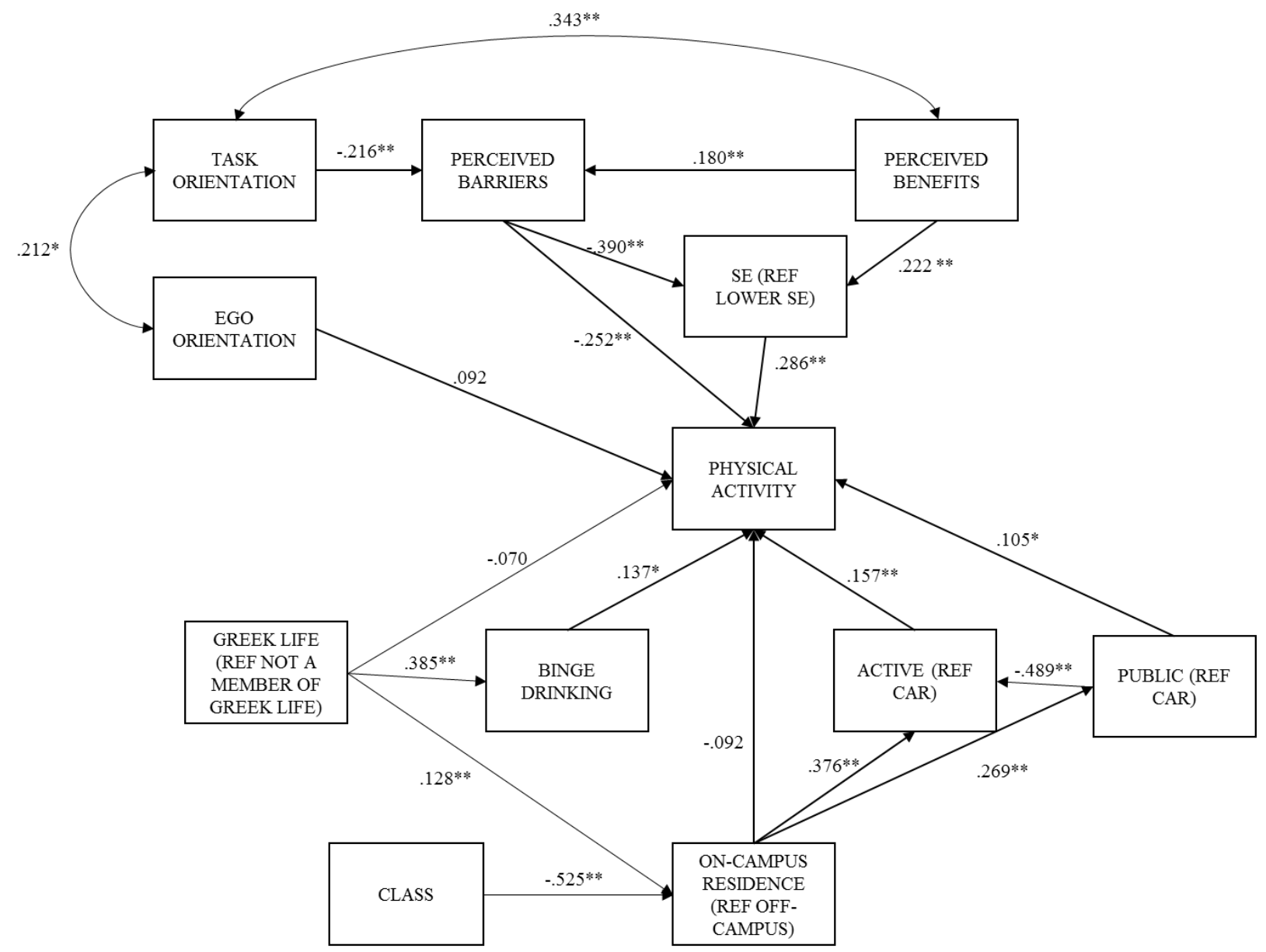

Note: SE (Ref Lower SE) = Self-Efficacy (Reference group Lower Self-Efficacy); Greek Life

$($ Ref not a member of Greek Life $)=$ Member of a Fraternity/Sorority (Reference group not a member of a Fraternity/Sorority); Active (Ref Car) = Active Transportation (Reference group Car); Public $($ Ref Car $)=$ Public Transportation (Reference group Car).

$* p<.05$

$* * p<.01$ 


\section{Appendix A. Extended Review of the Literature}

This literature review addressed research evidence regarding physical activity and alcohol use in US college students. The focus of this section is on environmental and intrapersonal factors. The literature is organized into the following sections. 1) Multi-theoretical and behavioral interventions, 2) Health Risks Associated with Physical Activity and Alcohol Consumption, 3) College Students' Physical Activity and Drinking Behaviors, 4) Socioecological Model, 5) Achievement Goal Theory, and 6) Summary.

\section{Multi-theoretical and Behavioral Interventions}

In a recent review, the authors summarized randomized (RCT) and non-randomized (NRCT) control trial interventions that promoted physical activity in university students (Maselli et al., 2018). The authors conducted a search of multiple online databases with terms related to physical activity, population, and type of intervention. In order to be included, studies had to be either a RCT or NRCT, quantitatively report physical activity, report on an intervention designed to promote university students' physical activity, and be published in English. Researchers used the Cochrane Collaboration tool for assessing risk of bias to code risk of bias in each study. Researchers initially identified 2585 articles. The number of articles was reduced to 2420 articles after removal of duplicates. After screening and full text assessment for eligibility, a total of 28 articles were included in the final analysis. The most common theoretical framework was Bandura's Social Cognitive Theory (used in 12 articles) (Maselli et al., 2018). Multiple studies (6) utilized more than one theory to inform intervention design. The majority of interventions (17) targeted only physical activity, however, eight targeted multiple health behaviors. In all but one of the effective interventions, researchers addressed multiple components of behavior, such 
as knowledge, motivation, and outcome expectations. Despite the effectiveness of these studies in changing physical activity behavior, all but one focused on individual or interpersonal factors and excluded environmental factors. Thus, there is a need to further investigate multiple factors that influence physical activity behavior. A combination of multiple theoretical approaches and behaviors may lead to greater insight into factors that predict physical activity behavior. These insights may help inform future research and practitioners working to increase physical activity on college campuses.

\section{Health Risks}

Relative intensity of physical activity has been linked to a decreased risk of developing coronary heart disease (Lee, Sesso, Oguma, \& Paffenbarger, 2003). A sample of 7,337 men from the Harvard Alumni Health Study were successfully followed from 1988 to 1995. The participants periodically received a questionnaire that assessed their health and health behaviors. Participants reported their daily and weekly activities and were asked to report frequency and duration (Lee et al., 2003). Intensity of activity was assessed with the Borg Scale. Other factors that may have impacted the development of coronary heart disease such as, weight, hypertension, and cholesterol. Coronary heart disease was assessed via self-report and a search of death certificates. Participants who expended 1000-2499 kcal per week in physical activity had a $20 \%$ decrease in rate of coronary heart disease across levels of physical activity. Thus it may be beneficial to consider not only duration but also intensity of exercise.

Another review found evidence for the relationship between physical activity and cardiovascular and all-cause mortality (Warburton et al., 2006). The authors searched for studies related to physical activity and cancer, diabetes, and cardiovascular disease among others. Studies were selected for review if they were considered exemplar instances of available 
evidence. Evidence supports the idea that physical activity is associated with reduced risk for allcause and cardiovascular mortality, diabetes, cancer and osteoporosis. These findings highlight the importance of physical activity in reducing the risk of developing chronic disease.

Furthermore, a dose response relationship between physical activity and chronic diseases has been established in the research (Kyu et al., 2016). For instance, a recent meta-analysis analyzed studies from multiple countries published from 1980 to 2016 . The review included a total of 174 articles that examined the relationship between physical activity and colon cancer (19), diabetes (55), heart disease (43), breast cancer (35) and stroke (26). Some studies included multiple of the aforementioned outcomes. Activity levels were split into four groups: insufficiently active, low active (600-3999 MET minutes), moderately active (4000-7999 MET minutes), and highly active ( $\geq 8000$ MET minutes). Individuals who met recommendations had a lower risk of developing chronic diseases compared to those who failed to meet recommendations. The risk of developing a chronic disease continued to decrease as level of activity increased. For example, the risk of breast cancer was reduced by $3 \%$ in the low active group and $6 \%$ in the moderately active group, and $14 \%$ in the highly active group compared to the insufficiently active group. The trend was the same for colon cancer $(10 \%, 17 \%, 21 \%)$, ischemic heart disease $(16 \%, 23 \%, 25 \%)$, diabetes $(14 \%, 25 \%, 28 \%)$, and ischemic stroke $(16 \%$, $19 \%, 26 \%)$. The authors noted there tends to be diminishing returns beyond the low level activity group. Regardless of domain of activity (i.e. leisure or active transport) physical activity can help reduce the risk of developing chronic diseases. Researchers have found that individuals who are physically active in early adulthood are more likely to be physically active later in life (Nogueira et al., 2009), thus the lack of physical activity during the college years can have a lasting impact on physical activity levels, and subsequent disease risk. 
In addition to the health benefits, researchers have reported a positive relationship between physical activity and academic success in college (Lipošek et al., 2019). Data was collected from a sample of 297 second year university students. The International Physical Activity Questionnaire (IPAQ; (Bailey et al., 1999) was used to assess level of physical activity. The researchers also measured physical fitness and took anthropometric measurements. Academic success was measured on a binary scale of regular admission or otherwise for students entering their second year of study. The majority of students $(79.8 \%)$ surveyed failed to meet recommendations for physical activity participation. However, students within the sample who exercised for 2-3 hours each week were more likely to have regular admission to their second year compared to students who exercised more or less than 2-3 hours per week. The researchers suggest that the benefits of physical activity for college students extends beyond health and into the classroom.

Moreover, sedentary behavior is associated with unhealthy behaviors in college students, such as poor diet (Pengpid et al., 2015). Data was gathered from 17,928 undergraduate students from 23 different countries and 24 universities. The International Physical Activity Questionnaire was used to measure physical activity. Additionally, anthropometric measurements, health risk behavior, personality and social variables, and health knowledge and perceived benefits were assessed. There was a wide range of physical inactivity prevalence across countries with percentages of inactive students ranging from 21.9 to $80.6 \%$. Across the sample, $41.4 \%$ of participants were inactive. Furthermore, physical inactivity was associated with skipping breakfast and a lack of social support. Whereas physical activity was associated with a lack of severe depressive symptoms in males. 
Physical inactivity and alcohol consumption associated with a number of health risks including chronic disease and a lack of social support (Kyu et al., 2016; Lee et al., 2012; Pengpid et al., 2015; Soedamah-Muthu et al., 2013). Meanwhile, physical activity is associated with reduced risk of chronic disease and favorable academic outcomes (Kyu et al., 2016; Lee et al., 2012; Lipošek et al., 2019). Given the risks associated with physical inactivity and alcohol consumptions, as well as the potential benefits of physical activity, it will be important to further understand the two health behaviors in college students.

\section{College Students' Physical Activity and Drinking Behaviors}

Despite knowing the link between these risk factors and the development of chronic disease, college students still fail to achieve recommended guidelines for activity, and subsequently, engage in unhealthy behaviors, such as consuming alcohol. The National College Health Assessment II (ACHA-NCHA II) is distributed in the Fall and Spring semesters to college students across the United States. Data is gathered through paper and electronic survey collection. The survey assesses information about students' perceptions of prevalent health topics, habits, and behaviors. The ACHA-NCHA II Spring 2019 reported data from 54,497 undergraduate college students. In accordance with the American College of Sports Medicine and American Heart Association (2007) guidelines, only 46.2\% of undergraduate students meet recommended levels of exercise (American College Health Association, 2019).

Alcohol consumption is one of the most common healthy behaviors studied in conjuncture with physical activity in US college students. The American College Health Association (2019) recently reported that $55.8 \%$ of the respondents reported they had consumed an alcoholic beverage within the previous 30 days leading up to the survey and one third, $33.3 \%$, 
of those who consumed alcohol reported doing something they regretted while drinking in the past 12 months (American College Health Association, 2019).

In addition to maintaining healthy levels of physical activity, college students are challenged to avoid unhealthy behaviors such as excessive alcohol consumption. Alcohol consumption has been shown to be positively associated with physical activity in college students (Abrantes et al., 2017; Graupensperger et al., 2018; Stuntz et al., 2017; Yoon et al., 2014). Yoon et al. (2014) examined the relationship between residence (on vs off campus) and different health behaviors in a sample of college students. Researchers collected data from college freshman. The data included location of residence, and various health behaviors, including physical activity. Male and female students that lived on campus had higher levels of physical activity compared to those who lived off campus. Female students living on-campus consumed more alcoholic beverages than those living off-campus. While these findings highlight potential differences between students living on/off campus, more research is needed as the sample size was small and predominately female. Additionally, this study does not account for the relationship between physical activity and alcohol consumption or other psychological variables.

Abrantes et al. (2017) sought to test a theorized processes that might illustrate the relationship between physical activity and alcohol use. Researchers measured alcohol use, physical activity, compensatory behavior, personality, motives, affective processes, and demographic variables in a sample of 132 college students. The authors used Confirmatory Factor Analysis to analyze between subject relationships. Students' level of exercise was positively correlated with their alcohol use. Gender predicted both exercise and alcohol consumption. Further, hierarchical linear modeling test found that exercising as a compensatory 
behavior for drinking explained the most variance. Despite the positive correlation between physical activity and alcohol, within subjects tests revealed that alcohol consumption was lower on the days that physical activity was higher. It is possible that other variables moderate or mediate the relationships between physical activity and alcohol use, such as environmental factors.

Additionally researchers have explored the relationship between psychosocial needs, physical activity, and health behaviors, such as alcohol consumption. Stuntz et al. (2017) surveyed 887 undergraduate students and measured self-determined motivation, physical activity, and psychological needs satisfaction. Similar to previous research, the amount of alcohol consumed while binge drinking and self-reported level of drinking were positively associated with leisure time physical activity. However, there was not a clear explanation of this association and the authors suggested this topic be explored further.

Graupensperger et al. (2018) examined the directionality of the relationship between physical activity and alcohol consumption in a sample of 396 college students. The authors collected data at three time points. Alcohol use predicted vigorous physical activity but not moderate physical activity at later time points. Neither moderate nor vigorous physical activity predicted alcohol consumption. While, the exact mechanism underlying the relationship was not examined, the researchers suggested the findings support the notion that exercise may serve as compensatory behavior for alcohol consumption which is in line with previous research (Graupensperger et al., 2018; Kilpatrick et al., 2003). However, researchers did not investigate the role of the environment or impact of college health promotion programs on alcohol consumption or physical activity. 
Kim, Larimer, Walker, and Mariatt (1997) examined the relationship between alcohol consumption and health-enhancing and health-compromising behaviors. Researchers sent an initial screening questionnaire was sent to 1,807 randomly selected incoming university students. A total of 381 students were invited to participate in the study (based on level of alcohol consumption). The authors successfully collected baseline data from 206 students in the fall semester. Researchers collected follow-up data from 188 students during the winter quarter. The researchers split participants into 4 categories: abstainers (no alcohol in the past year), lightmoderate (consumed alcohol at least once the past year and no more than two occasions per week, with no more than three at any one time), heavy drinkers (eclipsed two or more of the criteria for the light-moderate group), and episodic drinkers (reported consuming five or more drinks in one sitting over the course of the previous three months and drinking two times per week or less). The Daily Drinking Questionnaire was used to measure alcohol consumption. Respondents recorded how many drinks were consumed on each day of a normal week over the past three months and the number of hours usually spent consuming the drinks. The Computerized Lifestyle Assessment was used to measure emotional well-being, substance use, social issues, health maintaining activities, and preventive activities. The Brief Symptom Inventory was used to assess severity of a number of symptoms, including, anxiety, hostility, and psychoticism among others. Students' alcohol use was positively associated with the use of tobacco and illegal drug use. Contrary to other research, alcohol use was not associated with physical activity (Kim et al., 1997). Despite the lack of a relationship between physical activity and alcohol consumption, the authors suggest a reduction in alcohol use may impact other health behaviors. Thus, health behaviors may be connected and not independent of each other. 
In addition, researchers reported the pairing of physical activity and alcohol consumption occurs across the lifespan (Conroy et al., 2015). In this study data was gathered from a sample of 150 adults ranging in age from 19 to 89 years. A 21 -day measurement diary was completed three separate times by the participants. Day to day variations in physical activity were positively associated with alcohol use (Conroy et al., 2015). While these studies provide evidence for the relationship between physical activity and alcohol consumption, neither explored the factors that influence each behavior.

If alcohol consumption does in fact lead to increased levels of physical activity, it will be important to have a better understanding of this relationship, and factors that impact both behaviors, in order to reduce alcohol consumption without reducing physical activity. Therefore, an increased understanding of the relationship between these behaviors may allow groups and individuals responsible for student wellbeing to better utilize resources and design interventions to affect change where it matters. The socioecological model can provide a framework to incorporate multiple faucets of health behaviors and enhance understanding of the relationship between physical activity and alcohol consumption in college students.

\section{Socioecological Model}

Researchers have suggested that the provision of physical activity recommendations has not sufficiently increased physical activity levels (R. E. Rhodes et al., 2019). Thus, beginning in the late 1980's and early 1990's, theoretical frameworks began to be applied to the study of physical activity. One such framework is the socioecological approach (Rhodes et al., 2019). The social ecological approach incorporates influences at multiple levels ranging from the individual up to the government. This shared responsibility for behavior across levels makes this approach well suited for today given present mentality of Western society (R. E. Rhodes et al., 2019). 
Ecologic models have been around for decades and date back to the early 1950's (Sallis et al., 2008). Bronfenbrenner (1977) argued that in order to understand human behavior, researchers must go beyond simple observation of behavior and extend to examination of behavior across multiple settings and systems of interaction. Furthermore, he defined the ecology of human development as the relationship between the developing human and the ever changing environment in which it lives (Bronfenbrenner, 1977). This process is affected by relationships both within and between immediate surroundings, and broader formal and informal social contexts. Bronfenbrenner (1977) further proposed that the environment is made of different structures or systems (micro-, meso-, exo-, and macrosystems).

These systems are nested, such that, each successive system is contained in the next (Bronfenbrenner, 1977). The microsystem refers to the more immediate settings and relationships (personal) the individual interacts with. The microsystem includes settings such as home, work, or the classroom. Within each of the settings of the microsystem the individual might have a different role to fulfill (e.g. roommate, employee, student, etc.). The interactions between different microsystems comprise the mesosystem. The mesosystem might include interactions between work and school or peers and family. The next level up is the exosystem, or informal and formal systems that do not include the individual, but directly infringe upon or contain the individual's immediate surroundings. The exosystem includes the community the individual resides in and is made up of larger systems such as public transportation or media the individual is exposed to. Thus, the exosystem has the ability to influence what occurs in the small or lower levels of social ecological models. For instance, public transportation might influence a person's ability to travel from home to a gym. In addition, someone's social networks or the media they are exposed to might influence decisions or desire to engage in specific health 
behaviors. Lastly, the macrosystem refers to larger societal schemes that exist within a given culture or society. Macrosystems operate formally (government policies) and informally (cultural values). These systems transmit information, and give motivation and meaning to relationships across settings and systems (Bronfenbrenner, 1977). Bronfenbrenner (1977) proposed that what occurs between and within each of these systems is interdependent. That is, the processes and events of each system are related and even reciprocal in some cases. Furthermore, the environment may have both direct and indirect influences on a person's development and behavior. This nested systems approach helped inform future social ecological models (see Sallis et al., 2008).

The central theory of an social ecological model is that behavior is the result of various levels of interpersonal, intrapersonal, and environmental influences (Sallis et al., 2008). Social ecological models of health behavior contain four main assumptions. These assumptions are:

1. Multiple factors influence health behavior including interpersonal, intrapersonal, public policy, organizational, \& community levels

2. Interaction between behavioral influences occurs across levels

3. Ecologic models should identify the most relevant potential influences at each level and target a specific behavior

4. The most effective interventions for changing behavior target multiple levels of influence In other words, according to social ecological models, in order to effect substantial health behavior change, interventions must target both individual and environmental or policy level changes. Thus, social ecological models are well suited to inform health behavior interventions that aim to influence behavior at multiple levels (Sallis et al., 2008). 
Social ecological models propose behavior is influenced by both the person (attitudes, beliefs, etc.) and the environment (policies, culture, etc.) (Spence \& Lee, 2003). This is an added benefit that separates social ecological models from models that focus solely on the individual or environment. Changes made to influence behavior at the more distal levels can have a broader impact. Policy changes, for instance, may not only lead to broad environmental changes, but also impact how the individual interacts with the levels below where the change was made. Furthermore, proximal environments can buffer the impact of distal influences. Spence and Lee (2003), described an social ecological model in which physical activity behavior is influenced by biological processes, but not explained by them. Physical ecology has a direct influence on both psychological and biological factors. These influence or explain the relationship between physical ecology and behavior. Furthermore, Spence and Lee (2003) proposed the environment has both a direct and indirect impact on physical activity.

Earlier ecologic models such as Lewin's (1951) Ecological Psychology and Bronfenbrenner's (1979) Systems Theory, largely focused on explaining behavior (Sallis et al., 2008). However, over time, social ecological models have evolved to be more focused on application and seek to guide behavioral interventions (Sallis et al., 2008). Sallis and colleagues (2006) described an approach to physical activity intervention(s) based on ecological models. The authors argued that transitioning from a focus on individual or small-group interventions to multi-level interventions is more likely to achieve larger population wide range in behavior. Or in other words, multi-level interventions are more effective at widespread behavior change (Sallis et al., 2006). Thus, it is important to understand the impact of multiple levels on physical activity. 
Ecologic models may provide an ideal approach to assessing facilitators and barriers to physical activity, since individuals typically engage in physical activity in specific places (Sallis et al., 2006). Sallis and colleagues (2006) presented a social ecological model with four domains of active living (active recreation, active transport, occupational activities, and household activities). The separate domains occur across environments and can share some commonalities. For instance, rail trails (or walking trails) can provide an environment for recreation and be utilized as transportation to get from home to school or work. Leisure and recreation researchers have examined barriers and facilitators of physical activity. Incorporating social, cultural, environment, and/or psychological variables may provide additional insight into the relationships between factors influencing physical activity behavior.

Bauman et al. (2012) examined and analyzed reviews of physical activity with a focus on individual, interpersonal, environmental, regional or national policies, and global factors across a wide array of age groups and cultures. Researchers noted that over time studies have expanded beyond individual factors and incorporated multiple levels of influence. Furthermore, only a few variables were found to be consistent correlates with level of physical activity. Included variables were reported health, intention, male sex, self-efficacy, previous physical activity, and family/social support (in adolescents). Within environmental attributes, recreation facilities and locations, transportation environment, and aesthetics were found to be the strongest correlates with physical activity. Thus, environmental and personal factors both may influence the physical activity behavior of college students.

Researchers have used the socio-ecologic model as a framework to examine physical activity determinants in first year Nigerian university students (Essiet et al., 2017). Two faculties (Arts and Social Sciences) were randomly selected. Stratified random sampling was used to 
select students from the two faculties. Surveys were distributed to three hundred and eighty six first year students (Essiet et al., 2017). The survey measured physical activity (International Physical Activity Questionnaire, IPAQ Research Committee, 2005)), demographic variables, psychosocial factors (self-efficacy for physical activity, knowledge, attitude, and perceived barriers), social environment (availability of indoor and outdoor recreation facilities, and perceived attractiveness of scenery, and safety), and policy factors (perception of physical education classes and university allotted time for physical activity). Three hundred and forty-two students completed the survey. The majority of students (93.6\%) reported sufficient levels of physical activity, as defined by exceeding 600 MET-minutes over the previous week. Students with high self-efficacy had higher levels of physical activity compared to students with low selfefficacy. Furthermore, the only physical environment factor related to sufficient physical activity was availability of indoor recreation facilities. This study provides support for the investigation into multiple environmental and individual factors that might influence physical activity among college students. However, the sample was very active and likely not representative of most US students. Further, the researchers did not account for the role of access, such as transportation or distance from facilities.

The sedentary nature of being a student can make achieving recommended levels of physical activity difficult in the university setting. Essaw and colleagues (2019) investigated the dietary habits and physical activity behavior of a sample of undergraduate students in a university in Ghana. Stratified sampling was used to collect data from two hundred and seventyeight students across 6 degree fields. Data collected included anthropometric measurements, blood pressure, heart rate, and the Arab teens lifestyle study (included sections pertaining to demographics, physical activity, and dietary behaviors). More students (60.6\%) participated in 
physical activity for health reasons than for recreation reasons $(11.1 \%)$. The sample failed to meet physical activity recommendations and exhibited a largely sedentary lifestyle. The authors provided possible explanations as to why the sample was predominately sedentary. They speculated that the amount of time students spend in lecture, the library, and the role of the transportation system could all contribute. These researchers were able to provide an overview of physical activity behavior in a sample of Ghanaian university students. However, it does little to investigate determinants of behavior.

Furthermore, researchers have investigated the relationship between proximity to recreation facilities and physical activity with mixed results (Allen \& Ross, 2013; Staten et al., 2005). Allen and Ross (2013) investigated the relationship between perceived use and proximity to fitness facilities in a sample of 40 college students. Physical activity was measured with the Godin Leisure-Time Exercise Questionnaire. Respondents provided their residence and location of preferred place for physical activity. The survey also included questions from the Perceived Environments Related to Physical Activity Questionnaire and demographic questions. The average distance students traveled to their primary location of physical activity was 1.84 miles. Many students $(65 \%)$ reported walking to their primary location for physical activity from their residence. The majority of respondents $(62.5 \%)$ reported the university fitness center was their primary location of physical activity. There was not a significant relationship between proximity and level of physical activity. However, availability of exercise equipment in the home was significantly positively related to the level of strenuous physical activity. Contrary to previous studies (e.g., Staten et al., 2005) there was not a significant relationship between proximity preferred fitness facility and physical activity. However, this study utilized a limited sample size 
and more research is needed to investigate the relationship between proximity and level of physical activity.

Moulin and Irwin (2017) investigated daily sedentary time, as well as, facilitators and barriers to decreased sedentary time in a sample of undergraduate students at a Canadian university. Data was collected from 102 fulltime students. The three part online survey contained demographic information items, SIT-Q Sedentary Behavior Questionnaire, and items assessing participants' perceptions of barriers and facilitators to lowering sedentary time. Respondents were engaged in sedentary behaviors for an average of 11.88 hours per day. Students identified sitting in class and studying as barriers to physical activity. Conversely, students reported walking to and around campus and access to the university gym as facilitators to reducing sedentary behavior. While the study focused on sedentary behavior, researchers highlighted several ways sedentary time could be reduced and physical activity increased. The researchers noted several ways to reduce sedentary time, such as, access to the student gym, and active transportation (i.e. walking). Both factors can be incorporated into a socioecological approach and can be influenced by location of residence.

Additionally, researchers have investigated the relationship between the availability of home exercise equipment, proximity to an exercise facility, and level of physical activity in college students (Reed \& Phillips, 2005). Reed and Phillips (2005) collected data from a stratified sample of college students. The Godin Leisure Time Exercise Questionnaire was used to measure level of physical activity. A modified version of the Home Environment Exercise Questionnaire was used to assess quantity of home exercise equipment. The questionnaire was modified to included equipment typically owned by college students. In all, data was collected from a total of 422 students. The majority of students sampled $(66.7 \%)$ participated in physical 
activity less than two thirds of a mile from their residence. There was a significant positive relationship between proximity of residence to location of physical activity and the intensity level of physical activity. Furthermore there was a significant positive relationship between duration of physical activity and proximity of residence to location of activity. That is, the further the exercise facility was from the student's residence the longer in duration and the higher in intensity the physical activity was. Freshman and sophomore students engaged in physical activity closer to their residence and had more weekly bouts of physical activity compared to junior and senior students. An increase in availability of home exercise equipment was associated with an increase in physical activity. These findings suggest that proximity of exercise facilities and access to equipment at home can positively relate to physical activity participation in college. Thus, living on campus and having access to reliable transportation may increase students' engagement in physical activity behaviors.

Research has found that multiple factors, including environmental factors, are important in determining students use of the campus rec facility (Shaikh, Patterson, Lanning, Meyer, \& Patterson, 2018). Researchers measured level of physical activity, exercise self-efficacy, social physique anxiety, comfort in the exercise environment, and demographic variables in a sample of 189 undergraduate students. The only demographic variable related to facility use was being male. Additionally, level of strenuous physical activity, total physical activity, strength training, comfort in the environment, low social physique anxiety, and greater exercise self-efficacy were all positively associated with campus rec facility use. The final regression model explained over $30 \%$ of the variance in days per week students used the campus recreation facility. Comfort in the environment, days per week of strenuous activity, and affiliation with Greek life positively predicted facility use. Race (specifically being white), school year classification, and a focus on 
cardiovascular fitness negatively predicted facility use. While these results demonstrate both personal and environmental factors impact behavior, they failed to account for other environmental factors such as how near or far the students lived from campus.

Furthermore, Staten and colleagues (2005) assessed factors (environmental and institutional) that facilitate or prevent physical activity and the amount and type of physical activity students engage in. Researchers gathered data from a random sample of 531 students. The data collected included weekly physical activity, demographic information, dietary habits, as well as environmental factors that influence biking and walking. Analysis indicated students with roommates participated in more strengthening and vigorous physical activity compared to those who lived alone. Additionally, students living on campus reported higher levels of moderate physical activity compared to those who lived off campus. This research highlights the potential role of the environment (on vs off campus) but fails to examine the role of psychosocial variables such as goal orientation.

Researchers have linked various factors to beginning binge drinking behavior in adolescents who transitioned from high school to college (Weitzman et al., 2003). Data from the 1999 Harvard School of Public Health College Alcohol Study (CAS) was used to compare students who began binge drinking (uptake) and those who did not (non-uptake) during their first year of college. Surveys were sent to a random sample of students from 128 different colleges. Final data included responses from 119 colleges and 1894 freshman students (Weitzman et al., 2003). Respondents were divided into groups based on alcohol consumption. Participants that did no binge drink in high school and did binge drink sometime in the past 2-weeks prior to completing the survey were categorized as uptake drinkers. The non-uptake drinkers did not binge drink in high school or in the 2-weeks prior to completion of the survey. Those students 
who abstained from alcohol use were also included in the non-uptake group. The factors investigated included sociodemographic characteristics, prior drinking behaviors, perceived alcohol accessibility, social influences and affiliations, alcohol related norms, and other risk behaviors (Weitzman et al., 2003). The majority of the sample reported they had abstained (36\%) or drank but did not binge drink (38\%) over the past year. The uptake group contained $26 \%$ of the sample (Weitzman et al., 2003). Environmental factors, such as, access to cheap alcohol, social circles in which binge drinking is common, and physical surroundings where drinking is common increased the likelihood a student would begin binge drinking. Furthermore, a student's residence was associated with uptake of binge drinking. Students in the uptake group were more likely to live on-campus and less likely to report living with parents or in off-campus housing compared to the non-uptake group. This study provides support for the idea that location of residence can play a role in alcohol consumption. However, the data was limited to first year students aged 19 or younger and thus the results may not be applicable to students who begin drinking later in their college or experience.

As stated earlier, one of the main assumptions of social ecological models of health behavior is that both environmental and intrapersonal factors can influence health behavior (Sallis et al., 2008). Environmental factors such as living on-campus or nearer to recreation facilities have been positively associated with physical activity levels and alcohol consumption and in college students. While, motivation is an example of an intrapersonal factors that has been shown to be positively associated with physical activity in college students (Zizzi et al., 2006).

\section{Achievement Goal Theory}

Researchers have proposed a number of approaches to studying motivations (ex. Nicholls, 1984; Ryan \& Deci, 2000). One such approach, achievement motivation, describes 
contexts people aim to demonstrate high ability, or avoid demonstrating low ability to self or others (Nicholls, 1984). Achievement goal theory describes how individuals define success in specific achievement contexts and thus how they are motivated to reach their goal success (Nicholls, 1989; Roberts et al., 1998). In one form, individuals judge ability based on their own skill mastery. This is known as task orientation (Nicholls, 1984). In contrast, with an ego orientation, individuals judge ability based on comparison to the ability of others or some normative standard. These variations can lead to some differences. For instance, tasks requiring more effort for master can signal greater ability in a task orientation. Meanwhile, in an ego orientation, individuals define ability as being successful in tasks where others may have failed. The two orientations also differ on end goals. In task involvement the goal is improvement and learning. Whereas an ego involvement lends itself to demonstration of ability, thus mastery and learning are means to an end (comparison to others) rather than the goal itself. Thus task involvement is likely to produce greater effort compared to ego involvement.

Orientation, task or ego, may be determined, in part, by individual dispositions or circumstances (Duda \& Nicholls, 1992; Nicholls, 1989; Roberts et al., 1998). In achievement goal theory, achievement goals are not just targets; rather they represent broad orientations toward tasks that include associated views about success, effort, ability, and purposes (Pintrich, 2000). Additionally, outcomes such as behavioral strategies may be tied to the patterns of these views.

Biddle, Wang, Kavussanu, and Spray (2003) conducted a systematic review of correlates of achievement goal theory. The correlates included beliefs about effort producing success, motives, competence, and measures of behavior among others. The review included a total of 98 studies and contained 110 independent samples. Task orientation was positively associated with 
beliefs about effort leading to success, perceptions of confidence, and adaptive achievement strategies, such as persistence. Ego orientation was positively associated with beliefs that ability leads to success, perceptions of confidence, and being motivated by recognitions and status. These findings suggest that a high task orientation my lead to more adaptive behaviors in the pursuit of continued exercise.

When individuals maintain a task orientation, subjective success is achieved through personal improvement and mastery (Duda, 1989), whereas, success in ego orientation is achieved via outperforming others. Duda (1989) hypothesized that ego orientation in sport would be related to extrinsic beliefs about sport, such as the use of sport get into college. Simultaneously, it was hypothesized that task orientation in sport would be associated with the belief that the participation in sport itself is important. In a sample of high school athletes, researchers reported that task orientation was associated with belief that sport should teach prosocial behaviors such as working with others, honesty, and respect (Duda, 1989). A task orientation was also associated with the belief that sport should enhance/increase someone's ability to engage in life long physical activity. On the other hand, ego orientation was associated with the belief that sport can provide superficial boosts and personal gains. For instance, an example of a personal gain for students may be to use sport to increase social status and earn more money. Task involvement then, may yield sustained effort and persistence in the face of obstacles.

Duda and Nicholls (1992) wanted to compare relationships among goal orientations, satisfaction and perceived ability for sport and school. The researchers from 207 high school students. The authors found that goal orientation beliefs about success remained consistent across sport and school work. That is in both sport and school, task orientation was associated with the belief that success was related to effort, interest, and working with peers. On the other 
hand, ego orientation was associated with the belief that success requires high ability. While these findings came from sport and schoolwork it might be possible that task orientation is related to more effort in physical activity as well.

Murphy et al. (2019) examined the relationship between psychosocial variables and physical activity. Data, included demographic variables, level of physical activity, and psychosocial variables from 6,951 university students was analyzed. Psychosocial factors included motivation, social influences, environmental perceptions, and beliefs about capabilities among others. More females than males reported no physical activity. Students were separated into 5 clusters: Low Active, Active Commuters, Active in University, Active Outside University, and High Active. The researchers found that an increase in travel time to university was related to lower physical activity. Motivation and planning factors were positively associated with belonging to one of the Active clusters. However, this study did not specify the types of goals or forms of motivation (ex. Task vs Ego), factors that can influence persistence, and willingness to overcome challenges.

Individuals with a task orientation define success as a function of persistence and effort, whereas, individuals with an ego orientation view success in relation to comparisons to others. Thus ego involved individuals are likely to produce desirable behaviors only when they have high perceived competence. Kilpatrick et al. (2003) gathered data from 204 college students and measured task and ego orientation with a Goal Orientation in Exercise Scale. Males were more ego oriented than females. Furthermore, task orientation was positively associated with exercise intensity, years exercising, and exercise enjoyment, while ego orientation was not significantly correlated to these constructs. As noted by Kilpatrick et al. (2003) a better understanding of exercise behavior will occur with further acknowledgement of the role of goal orientations in 
exercise behaviors. One approach to furthering the understanding of exercise behavior, may be to expand research beyond the individual and incorporate environmental factors.

Zizzi, Keeler, and Watson II (2006) sought to examine the link between goal orientation and stage of change. Researchers also developed and tested the reliability and validity of the Perceptions of Success Questionnaire for Exercise (POSQ-E). Researchers collected data from 569 students who utilized the campus recreation center an average of 3.77 days per week. Initial findings suggest support for the reliability and validity of the POSQ-E. Researchers found differences between goal orientation groups, task vs. ego. For instance, men were more likely to be in the high task/high ego group and less likely to be in the low task/low ego group compared to women. Students who exercised regularly were more likely to be in the high task/high ego group than non-exercisers. The low task/low ego group contained the largest number of nonexercisers. Furthermore, the two high task groups (high task/high ego and high task/low ego) were more inclined than those in the low task groups to support beliefs that physical activity provides personal benefits independent of comparison to others. These personal benefits include the notion that exercise leads to feeling better physically, is enjoyable, leads to a sense of personal accomplishment, eases feelings of tiredness, leads to an increased feeling of mental alertness, and enhances self-esteem. A repeated measures ANOVA revealed significant interaction between stage of change and goal type. Furthermore, as individuals transition towards sustainment of physical activity (maintenance stage), students continued or increased level of task focus, while their reliance on ego reference cues decreased. As pointed out by Zizzi et al. (2006), the environment of the exerciser (instructor, facility, etc.) may influence goal orientation. Thus, there may be individual differences that occur between students who use or don't use student recreation centers for physical activity. 
Student recreation users and non-users. In order to increase understanding of factors that contribute to physical activity of college students several researchers have generated descriptions of users and non-users of campus recreation facilities (Castle et al., 2015; Miller et al., 2008; Watson et al., 2006). For instance, Watson and colleagues (2006) identified differences between users and non-users of a student recreation facility. Researchers surveyed 665 users and non-users. Significantly more non-users put themselves in pre-contemplative or contemplative stage compared to facility users. Conversely more users were classified as action or maintenance stage than non-users. The majority of users reported motivation that is task oriented in nature such as always trying to improve conditions. Researchers also found students who exercise more than 4 hours per week were more likely to report the campus rec center has increased quality of student life. Non-users were more likely to report they lived off campus. Students reported that not having someone to exercise with was a barrier to using the facility. These findings highlight the importance of individual and microsystems aspects, motivation and social support, for physical activity. However, because of the statistical methodology, the researchers fail to explain more specific relationships between these psychosocial variables and the environment.

Researchers recently investigated factors that influence usage and non-usage of a student recreation facility in a sample of undergraduate students (Castle et al., 2015). These factors included demographics such as age, year in college, gender, and environmental factors such as such as transportation and living situation. Among other factors, a student's living situation, extra-curricular activities, and transportation all influenced their usage of the student recreation facility. Typical facility users spent between 45 and 60 minutes in the facility, primarily performed resistance and cardiovascular training, and walked to the facility. Males and females reported losing or maintaining weight as significant motivators to use the facility. Most of the 
users lived either on-campus or off-campus but within one mile of the campus. Furthermore, the most statistically significant factor that influenced non-usage of the facility was living distance from campus. While this research provides evidence for factors related to facility use among undergraduate students, it failed to assess facility specifics that may serve as aids or barriers to usage.

In addition, Miller et al. (2008) examined characteristics of undergraduate students who use and do not use campus recreation facilities. Surveys were mailed out to a random sample of 1,700 undergraduate students. The survey data included demographics, weight perception, risk behaviors (alcohol, tobacco, and other drug use), and recreation facility use. The majority of respondents reported they were trying to change their weight and consumed alcohol in the past 30 days. Slightly less than half of participants reported using the facility at least once per week. The students participated in activities that included weight lifting, walking or running, and stretching. A higher percentage of men used the facility compared to women. Lower-division students and those who lived on campus were more likely to use the facility compared to higherdivision students and those who lived off campus respectively. Facility users were also more likely to report wanting to change their weight. Students who consumed alcohol in the past 30 days were more likely to report using the facility than those who had not. Women were only about two-thirds times as likely as men to use the facility. Students living on campus were $50 \%$ more likely to use the facility compared to students who lived off-campus. Additionally, students belonging to a Greek organization were nearly twice as likely to use the facility compared to those not belonging. The typical profile of a campus rec user in this sample is a young male member of a fraternity. These findings support a possible association between alcohol use and physical activity and reinforce the need for further study of these two health behaviors. 
Nevertheless, the study did not incorporate how environment might act on factors such as motivation in determining or explaining why this is the typical profile of users.

\section{Summary}

The negative health consequences of alcohol consumption and physical inactivity are well established (Kyu et al., 2016; Lee et al., 2012; Soedamah-Muthu et al., 2013; Warburton et al., 2006). Moreover, researchers have presented a positive association between alcohol consumption and physical activity behavior in college students (Abrantes et al., 2017; Graupensperger et al., 2018; Stuntz et al., 2017). Promoting physical activity, while reducing alcohol consumption in college students may be even more important, as these two behaviors have been shown to be associated across the lifespan (Conroy et al., 2015).

Recent research has highlighted the importance of addressing multiple components of behavior when implementing interventions (Maselli et al., 2018). The socioecologic models can provide a framework for incorporating environmental and individual components of behavior (Sallis, 2018; Sallis et al., 2006). In line with the socioecological approach, several environmental and interpersonal factors have been identified as having an association with physical activity and alcohol consumption in college students, including motivation and living on- or off-campus (Castle et al., 2015; Murphy et al., 2019; Staten et al., 2005; Weitzman et al., 2003; Zizzi et al., 2006).

However, the interaction of these factors is unclear, and thus researchers have yet to establish why alcohol consumption (a risky health behavior) is positively associated with physical activity (a health promoting behavior). Researchers have suggested that physical 
activity is a compensatory behavior that occurs as a result of alcohol consumption. More longitudinal studies may shed light on which of these behaviors is leading to the other.

Additionally, researchers can investigate what other factors, such as social norms and/or understanding of physical activity and drinking habits, which may contribute students attempting to compensate for drinking. More research is needed to advance the understanding of these relationships. Additional multivariate research is needed to further examine these relationships.

Future research may also consider, gender differences, Greek life affiliation, ease of access to affordable alcohol and physical activity opportunities. Students who live in fraternity or sorority housing or are affiliated with Greek life are more likely to utilize on campus recreation facilities and begin binge drinking (Miller et al., 2008; Shaikh et al., 2018; Weitzman et al., 2003). Multivariate longitudinal research can help establish what variables impact alcohol consumption and physical activity levels and how those variables may change over time. These findings can help inform interventions.

Interventions that target multiple components of health behavior have been shown to be effective. Successful interventions with college students can help inform college wellness programs and help them target key behavioral components. Through this approach, colleges and universities may be able to help their students maintain or increase their physical activity, while reducing their alcohol consumption. 


\section{References}

Abrantes, A. M., Scalco, M. D., O’Donnell, S., Minami, H., \& Read, J. P. (2017). Drinking and exercise behaviors among college students: Between and within-person associations. Journal of Behavioral Medicine, 40(6), 964-977. https://doi.org/10.1007/s10865-0179863-X

Allen, R., \& Ross, C. M. (2013). An assessment of proximity of fitness facilities and equipment and actual perceived usage by undergraduate university students: A pilot study. Recreational Sports Journal, 37(2), 123-135. https://doi.org/10.1123/rsj.37.2.123

American College Health Association. (2014). American College Health Association-National College Health Assessment II: ACHA-NCHA II Sample Survey.

American College Health Association. (2018). American College Health Association-National College Health Assessment II: Undergraduate Student Executive Summary Fall 2018. American College Health Association.

American College Health Association. (2019). American College Health Association-National College Health Assessment II: Undergraduate Student Executive Summary Spring 2019. American College Health Association.

Arterberry, B. J., Smith, A. E., Martens, M. P., Cadigan, J. M., \& Murphy, J. G. (2014). Protective behavioral strategies, social norms, and alcohol-related outcomes. Addiction Research \& Theory, 22(4), 279-285. https://doi.org/10.3109/16066359.2013.838226

Bailey, D. A., Mckay, H. A., Mirwald, R. L., Crocker, P. R. E., \& Faulkner, R. A. (1999). A SixYear Longitudinal Study of the Relationship of Physical Activity to Bone Mineral Accrual in Growing Children: The University of Saskatchewan Bone Mineral Accrual Study. Journal of Bone and Mineral Research, 14(10), 1672-1679. https://doi.org/10.1359/jbmr.1999.14.10.1672 
Ball, J. W., Bice, M. R., \& Maljak, K. A. (2018). Exploring the Relationship Between College Students' Barriers to Exercise and Motivation. American Journal of Health Studies, 33(2), 61-69.

Bandura, A. (1982). Self-efficacy mechanism in human agency. American Psychologist, 37(2).

Bandura, A. (2004). Health promotion by social cognitive means. Health Education \& Behavior: The Official Publication of the Society for Public Health Education, 31(2), 143-164. https://doi.org/10.1177/1090198104263660

Barry, A., Madson, M., Moorer, K., \& Christman, K. (2016). Predicting Use of Protective Behavioral Strategies: Does Fraternity/Sorority Affiliation Matter? Journal of Student Affairs Research and Practice, 53(3), 294-304. https://doi.org/10.1080/19496591.2016.1165107

Bauman, A. E., Reis, R. S., Sallis, J. F., Wells, J. C., Loos, R. J., Martin, B. W., \& Lancet Physical Activity Series Working Group. (2012). Correlates of physical activity: Why are some people physically active and others not? The Lancet, 380(9838), 258-271.

Biddle, S., Wang, C. K. J., Kavussanu, M., \& Spray, C. (2003). Correlates of achievement goal orientations in physical activity: A systematic review of research. European Journal of Sport Science, 3(5), 1-20. https://doi.org/10.1080/17461390300073504

Bray, S. R. (2007). Self-Efficacy for Coping With Barriers Helps Students Stay Physically Active During Transition to Their First Year at a University. Research Quarterly for Exercise and Sport, 78(2), 61-70. https://doi.org/10.1080/02701367.2007.10599404

Bronfenbrenner, U. (1977). Toward an experimental ecology of human development. American Psychologist, 32(7), 513-531. https://doi.org/10.1037/0003-066X.32.7.513

Bronfenbrenner, U. (1979). The Ecology of Human Development. Harvard University Press. 
Buscemi, J., Martens, M. P., Murphy, J. G., Yurasek, A. M., \& Smith, A. E. (2011). Moderators of the Relationship Between Physical Activity and Alcohol Consumption in College Students. Journal of American College Health, 59(6), 503-509. https://doi.org/10.1080/07448481.2010.518326

Castle, J., Alman II, R., Kostelnik, R., \& Smith, S. (2015). Factors that affect the usage of fitness and recreation centers by students on college campuses. Journal of Physical Education and Sports Management, 2(2). https://doi.org/10.15640/jpesm.v2n2a8

Chu, T. L., Zhang, T., \& Li, H. (2019). Roles of Physical Activity Type in Exercise Motivational Profiles and Behavioral Frequencies Among College Freshmen. 13.

Conroy, D. E., Ram, N., Pincus, A. L., Coffman, D. L., Lorek, A. E., Rebar, A. L., \& Roche, M. J. (2015). Daily physical activity and alcohol use across the adult lifespan. Health Psychology, 34(6), 653-660. https://doi.org/10.1037/hea0000157

Davis, H. A., Riley, E. N., Smith, G. T., Milich, R., \& Burris, J. L. (2017). Alcohol use and strenuous physical activity in college students: A longitudinal test of 2 explanatory models of health behavior. Journal of American College Health, 65(2), 112-121. https://doi.org/10.1080/07448481.2016.1260571

Duda, J. L. (1989). Relationship between task and ego orientation and the perceived purpose of sport among high school athletes. Journal of Sport and Exercise Psychology, 11(3), 318335. https://doi.org/10.1123/jsep.11.3.318

Duda, J. L., \& Nicholls, J. G. (1992). Dimensions of achievement motivation in schoolwork and sport. Journal of Educational Psychology, 84(3), 290-299. https://doi.org/10.1037/00220663.84.3.290 
Essaw, E., Moses, M. O., Afrifa, D., Acheampong, I. K., Mensah, W., \& Owusu, L. (2019). Physical activity patterns and dietary habits of undergraduate students. Baltic Journal of Health and Physical Activity, 11(1), 115-123. https://doi.org/10.29359/BJHPA.11.1.12

Essiet, I. A., Baharom, A., Shahar, H. K., \& Uzochukwu, B. (2017). Application of the SocioEcological Model to predict physical activity behaviour among Nigerian University students. The Pan African Medical Journal, 26, 14.

Farren, G. L., Zhang, T., Martin, S. B., \& Thomas, K. T. (2017). Factors related to meeting physical activity guidelines in active college students: A social cognitive perspective. Journal of American College Health, 65(1), 10-21. https://doi.org/10.1080/07448481.2016.1229320

Gardner, B. (2015). A review and analysis of the use of 'habit' in understanding, predicting and influencing health-related behaviour. Health Psychology Review, 9(3), 277-295. https://doi.org/10.1080/17437199.2013.876238

Gathman, P. C., Grabowski, N. R., Carr, J. W., \& Todd, M. K. (2017). Campus Recreation Use and Health Behaviors among College Students in Different Academic Disciplines. Recreational Sports Journal, 41(1), 87-99. https://doi.org/10.1123/rsj.2016-0011

Graupensperger, S., Wilson, O., Bopp, M., \& Blair Evans, M. (2018). Longitudinal association between alcohol use and physical activity in US college students: Evidence for directionality. Journal of American College Health, 1-8. https://doi.org/10.1080/07448481.2018.1536058

Grubbs, L., \& Carter, J. (2002). The Relationship of Perceived Benefits and Barriers to Reported Exercise Behaviors in College Undergraduates: Family \& Community Health, 25(2), 7684. https://doi.org/10.1097/00003727-200207000-00009 
Guthold, R., Stevens, G. A., Riley, L. M., \& Bull, F. C. (2018). Worldwide trends in insufficient physical activity from 2001 to 2016: A pooled analysis of 358 population-based surveys with 1.9 million participants. The Lancet Global Health, 6(10), e1077-e1086. https://doi.org/10.1016/S2214-109X(18)30357-7

Gyurcsik, N. C., Bray, S. R., \& Brittain, D. R. (2004). Coping with barriers to vigorous physical activity during transition to university. Family \& Community Health, 27(2), 130-142.

Hagger, M. S., \& Chatzisarantis, N. L. D. (2014). An Integrated Behavior Change Model for Physical Activity. Exercise and Sport Sciences Reviews, 42(2), 62-69. https://doi.org/10.1249/JES.0000000000000008

Hingson, R. (2017). Magnitude and Trends in Heavy Episodic Drinking, Alcohol-Impaired Driving, and Alcohol-Related Mortality and Overdose Hospitalizations Among Emerging Adults of College Ages 18-24 in the United States, 1998-2014. JOURNAL OF STUDIES ON ALCOHOL AND DRUGS, 9.

Hooper, D., Coughlan, J., \& Mullen, M. (2008). Structural equation modelling: Guidelines for determining model fit. The Electronic Journal of Buisness Research Methods, 6, 53-60.

Horacek, T. M., Dede Yildirim, E., Kattelmann, K., Brown, O., Byrd-Bredbenner, C., Colby, S., Greene, G., Hoerr, S., Kidd, T., Koenings, M. M., Morrell, J., Olfert, M. D., Phillips, B., Shelnutt, K., \& White, A. (2018). Path Analysis of Campus Walkability/Bikeability and College Students' Physical Activity Attitudes, Behaviors, and Body Mass Index. American Journal of Health Promotion, 32(3), 578-586. https://doi.org/10.1177/0890117116666357

Hu, L., \& Bentler, P. M. (1999). Cutoff criteria for fit indexes in covariance structure analysis: Conventional criteria versus new alternatives. Structural Equation Modeling: A Multidisciplinary Journal, 6(1), 1-55. https://doi.org/10.1080/10705519909540118 
Hurley, K. S., Flippin, K. J., Blom, L. C., Hoover, D. L., \& Judge, L. W. (2018). Practices, Perceived Benefits, and Barriers to Resistance Training Among Women Enrolled in College. 14.

Ickes, M. J., McMullen, J., Pflug, C., \& Westgate, P. M. (2016). Impact of a University-based Program on Obese College Students' Physical Activity Behaviors, Attitudes, and Selfefficacy. American Journal of Health Education, 47(1), 47-55. https://doi.org/10.1080/19325037.2015.1111178

IPAQ Research Committee. (2005). Guidelines for data processing and analysis of the International Physical Activity Questionnaire (IPAQ)-short and long forms. http://www.ipaq.ki.se/scoring.pdf

Kilpatrick, M., Bartholomew, J., \& Reimer, H. (2003). The measurement of goal orientations in exercise. Journal of Sport Behavior, 26, 121-136.

Kilpatrick, M., Hebert, E., \& Bartholomew, J. (2005). College Students' Motivation for Physical Activity: Differentiating Men’s and Women's Motives for Sport Participation and Exercise. Journal of American College Health, 54(2), 87-94.

Kim, E. L., Larimer, M. E., Walker, D. D., \& Marlatt, G. A. (1997). Relationship of alcohol use to other health behaviors among college students. Psychology of Addictive Behaviors, 11(3), 166-173. https://doi.org/10.1037/0893-164X.11.3.166

King, K., Vidourek, R., English, L., \& Merianos, A. (2014). Vigorous physical activity among college students: Using the health belief model to assess involvement and social support. 14.

Kuperberg, A., \& Padgett, J. E. (2017). Partner Meeting Contexts and Risky Behavior in College Students' Other-Sex and Same-Sex Hookups. The Journal of Sex Research, 54(1), 55-72. https://doi.org/10.1080/00224499.2015.1124378 
Kyu, H. H., Bachman, V. F., Alexander, L. T., Mumford, J. E., Afshin, A., Estep, K., Veerman, J. L., Delwiche, K., Iannarone, M. L., Moyer, M. L., Cercy, K., Vos, T., Murray, C. J. L., \& Forouzanfar, M. H. (2016). Physical activity and risk of breast cancer, colon cancer, diabetes, ischemic heart disease, and ischemic stroke events: Systematic review and doseresponse meta-analysis for the Global Burden of Disease Study 2013. BMJ, i3857. https://doi.org/10.1136/bmj.i3857

Lally, P., van Jaarsveld, C. H. M., Potts, H. W. W., \& Wardle, J. (2010). How are habits formed: Modelling habit formation in the real world. European Journal of Social Psychology, 40(6), 998-1009. https://doi.org/10.1002/ejsp.674

Lee, I.-M., Sesso, H. D., Oguma, Y., \& Paffenbarger, R. S., Jr. (2003). Relative intensity of physical activity and risk of coronary heart disease. Circulation, 107(8), 1110-1116. https://doi.org/10.1161/01.CIR.0000052626.63602.58

Lee, I.-M., Shiroma, E. J., Lobelo, F., Puska, P., Blair, S. N., Katzmarzyk, P. T., \& Lancet Physical Activity Series Working Group. (2012). Effect of physical inactivity on major non-communicable diseases worldwide: An analysis of burden of disease and life expectancy. The Lancet, 380(9838), 219-229.

Lewin, K. (1951). Field theory in social science (C. D, Ed.). Harper.

Lipošek, S., Planinšec, J., Leskošek, B., \& Pajtler, A. (2019). Physical activity of university students and its relation to physical fitness and academic success. Annales Kinesiologiae, 9(2), 89-104. https://doi.org/10.35469/ak.2018.171

Maselli, M., Ward, P. B., Gobbi, E., \& Carraro, A. (2018). Promoting physical activity among university students: A systematic review of controlled trials. American Journal of Health Promotion, 32(7), 1602-1612. https://doi.org/10.1177/0890117117753798 
Miller, K. H., Noland, M., Rayens, M. K., \& Staten, R. (2008). Characteristics of users and nonusers of a campus recreation center. Recreational Sports Journal, 32(2), 87-96. https://doi.org/10.1123/rsj.32.2.87

Moulin, M. S., \& Irwin, J. D. (2017). An assessment of sedentary time among undergraduate students at a Canadian university. International Journal of Exercise Science, 10(8), 1161129.

Murphy, J. J., MacDonncha, C., Murphy, M. H., Murphy, N., Nevill, A. M., \& Woods, C. B. (2019). What psychosocial factors determine the physical activity patterns of university students? Journal of Physical Activity and Health, 16(5), 325-332. https://doi.org/10.1123/jpah.2018-0205

National Institude on Alcohol Abuse and Alcoholism. (2017). Drinking Levels Defined. https://www.niaaa.nih.gov/alcohol-health/overview-alcohol-consumption/moderatebinge-drinking.

Ng, J. Y. Y., Ntoumanis, N., Thøgersen-Ntoumani, C., Deci, E. L., Ryan, R. M., Duda, J. L., \& Williams, G. C. (2012). Self-Determination Theory Applied to Health Contexts: A MetaAnalysis. Perspectives on Psychological Science, 7(4), 325-340. https://doi.org/10.1177/1745691612447309

Nicholls, J. G. (1984). Achievement motivation: Conceptions of ability, subjective experience, task choice, and performance. Psychological Review, 91(3), 328-346. https://doi.org/10.1037/0033-295X.91.3.328

Nicholls, J. G. (1989). The competitive ethos and democratic education. Harvard University Press.

Nogueira, D., Faerstein, E., Rugani, I., Chor, D., Lopes, C. S., \& Werneck, G. L. (2009). Does leisure-time physical activity in early adulthood predict later physical activity? Pro-Saude 
Study. Revista Brasileira de Epidemiologia, 12(1), 3-9. https://doi.org/10.1590/S1415$790 \times 2009000100001$

Pengpid, S., Peltzer, K., Kassean, H. K., Tsala Tsala, J. P., Sychareun, V., \& MüllerRiemenschneider, F. (2015). Physical inactivity and associated factors among university students in 23 low-, middle- and high-income countries. International Journal of Public Health, 60(5), 539-549. https://doi.org/10.1007/s00038-015-0680-0

Pintrich, P. R. (2000). An achievement goal theory perspective on issues in motivation terminology, theory, and research. Contemporary Educational Psychology, 25(1), 92104. https://doi.org/10.1006/ceps.1999.1017

Pratt, M., Perez, L. G., Goenka, S., Brownson, R. C., Bauman, A., Sarmiento, O. L., \& Hallal, P. C. (2015). Can population levels of physical activity be increased? Global evidence and experience. Progress in Cardiovascular Diseases, 57(4), 356-367.

Rebar, A. L., Dimmock, J. A., Jackson, B., Rhodes, R. E., Kates, A., Starling, J., \& Vandelanotte, C. (2016). A systematic review of the effects of non-conscious regulatory processes in physical activity. Health Psychology Review, 10(4), 395-407. https://doi.org/10.1080/17437199.2016.1183505

Reed, J. A., \& Phillips, D. A. (2005). Relationships between physical activity and the proximity of exercise facilities and home exercise equipment used by undergraduate university students. Journal of American College Health, 53(6), 285-290. https://doi.org/10.3200/JACH.53.6.285-290

Rhodes, N., Potocki, B., \& Thomas, S. (2019). Predicting College Student Drinking and Smoking Intentions With Cognitively Accessible Attitudes and Norms. Health Education \& Behavior, 46(2), 267-274. https://doi.org/10.1177/1090198118818238 
Rhodes, R. E., Janssen, I., Bredin, S. S. D., Warburton, D. E. R., \& Bauman, A. (2017). Physical activity: Health impact, prevalence, correlates and interventions. Psychology \& Health, 32(8), 942-975. https://doi.org/10.1080/08870446.2017.1325486

Rhodes, R. E., McEwan, D., \& Rebar, A. L. (2019). Theories of physical activity behaviour change: A history and synthesis of approaches. Psychology of Sport and Exercise, 42, 100-109. https://doi.org/10.1016/j.psychsport.2018.11.010

Rinker, D. V., Diamond, P. M., Walters, S. T., Wyatt, T. M., \& DeJong, W. (2016). Distinct Classes of Negative Alcohol-Related Consequences in a National Sample of Incoming First-Year College Students: A Latent Class Analysis. Alcohol and Alcoholism, 51(5), 7.

Roberts, G. C., Treasure, D. C., \& Balague, G. (1998). Achievement goals in sport: The development and validation of the Perception of Success Questionnaire. Journal of Sports Sciences, 16(4), 337-347. https://doi.org/10.1080/02640419808559362

Ryan, R. M., \& Deci, E. L. (2000). Self-determination theory and the facilitation of intrinsic motivation, social development, and well-being. American Psychologist, 55(1), 68.

Ryan, R. M., \& Deci, E. L. (2017). Self-determination theory: Basic psychological needs in motivation, development, and wellness. Guilford Press.

Sallis, J. F. (2018). Needs and challenges related to multilevel interventions: Physical activity examples. Health Education \& Behavior, 45(5), 661-667. https://doi.org/10.1177/1090198118796458

Sallis, J. F., Bull, F., Guthold, R., Heath, G. W., Inoue, S., Kelly, P., Oyeyemi, A. L., Perez, L. G., Richards, J., \& Hallal, P. C. (2016). Progress in physical activity over the Olympic quadrennium. The Lancet, 388(10051), 1325-1336. https://doi.org/10.1016/S01406736(16)30581-5 
Sallis, J. F., Cervero, R. B., Ascher, W., Henderson, K. A., Kraft, M. K., \& Kerr, J. (2006). An ecological approach to creating active living communities. Annual Review of Public Health, 27(1), 297-322. https://doi.org/10.1146/annurev.publhealth.27.021405.102100

Sallis, J. F., Owen, N., \& Fisher, E. B. (2008). Ecological models of health behavior. In K. Glanz, B. K. Rimer, \& K. Viswanath (Eds.), Health behavior and health education: Theory, research, and practice (pp. 465-485). Jossey-Bass.

Schwartz, J., Rhodes, R., Bredin, S., Oh, P., \& Warburton, D. (2019). Effectiveness of Approaches to Increase Physical Activity Behavior to Prevent Chronic Disease in Adults: A Brief Commentary. Journal of Clinical Medicine, 8(3), 295. https://doi.org/10.3390/jcm8030295

Shaffer, K., Bopp, M., Papalia, Z., Sims, D., \& Bopp, C. M. (2017). The Relationship of Living Environment with Behavioral and Fitness Outcomes by Sex: An Exploratory Study in College-aged Students. 11.

Shaikh, H. M., Patterson, M. S., Lanning, B., Umstattd Meyer, M. R., \& Patterson, C. A. (2018). Assessing college students' use of campus recreation facilities through individual and environmental factors. Recreational Sports Journal, 42(2), 145-159. https://doi.org/10.1123/rsj.2017-0033

Simons, D., Clarys, P., De Bourdeaudhuij, I., de Geus, B., Vandelanotte, C., \& Deforche, B. (2014). Why do young adults choose different transport modes? A focus group study. Transport Policy, 36, 151-159. https://doi.org/10.1016/j.tranpol.2014.08.009

Soedamah-Muthu, S. S., De Neve, M., Shelton, N. J., Tielemans, S. M. A. J., \& Stamatakis, E. (2013). Joint associations of alcohol consumption and physical activity with all-cause and cardiovascular mortality. The American Journal of Cardiology, 112(3), 380-386. https://doi.org/10.1016/j.amjcard.2013.03.040 
Spence, J. C., \& Lee, R. E. (2003). Toward a comprehensive model of physical activity. Psychology of Sport and Exercise, 4(1), 7-24. https://doi.org/10.1016/S14690292(02)00014-6

Staten, R. R., Miller, K., Noland, M. P., \& Rayens, M. K. (2005). College students' physical activity: Application of an ecological perspective. American Journal of Health Studies, $20(1), 58-65$.

Stuntz, C. P., Smith, C., \& Vensel, K. (2017). Is the relationship between lifestyle factors and physical activity mediated by psychological needs and motivation? International Journal of Sport and Exercise Psychology, 15(3), 291-305. https://doi.org/10.1080/1612197X.2015.1079923

Sukys, S., Cesnaitiene, V. J., Emeljanovas, A., Mieziene, B., Valantine, I., \& Ossowski, Z. M. (2019). Reasons and Barriers for University Students' Leisure-Time Physical Activity: Moderating Effect of Health Education. Perceptual and Motor Skills, 126(6), 1084-1100. https://doi.org/10.1177/0031512519869089

Teixeira, P. J., Carraça, E. V., Markland, D., Silva, M. N., \& Ryan, R. M. (2012). Exercise, physical activity, and self-determination theory: A systematic review. The International Journal of Behavioral Nutrition and Physical Activity, 9(Journal Article). https://doi.org/10.1186/1479-5868-9-78

Thompson, C. M., \& Romo, L. K. (2016). College Students’ Drinking and Posting About Alcohol: Forwarding a Model of Motivations, Behaviors, and Consequences. Journal of Health Communication, 21(6), 688-695. https://doi.org/10.1080/10810730.2016.1153763

Towne, S. D., Ory, M. G., Smith, M. L., Peres, S. C., Pickens, A. W., Mehta, R. K., \& Benden, M. (2017). Accessing physical activity among young adults attending a university: The 
role of sex, race/ethnicity, technology use, and sleep. BMC Public Health, 17(1), 721. https://doi.org/10.1186/s12889-017-4757-y

Tran, D.-M. T., Zimmerman, L. M., Kupzyk, K. A., Shurmur, S. W., Pullen, C. H., \& Yates, B. C. (2017). Cardiovascular risk factors among college students: Knowledge, perception, and risk assessment. Journal of American College Health, 65(3), 158-167. https://doi.org/10.1080/07448481.2016.1266638

Tyler, K. A., Schmitz, R. M., Adams, S. A., \& Simons, L. G. (2017). Social factors, alcohol expectancy, and drinking behavior: A comparison of two college campuses. Journal of Substance Use, 22(4), 357-364. https://doi.org/10.1080/14659891.2016.1223762

Warburton, D. E., Nicol, C. W., \& Bredin, S. S. (2006). Health benefits of physical activity: The evidence. CMAJ: Canadian Medical Association Journal, 174(6), 801-809. https://doi.org/10.1503/cmaj.051351

Watson, J. C., Ayers, S. F., Zizzi, S., \& Naoi, A. (2006). Student recreation centers: A comparison of users and non-users on psychosocial variables. Recreational Sports Journal, 30(1), 9-19. https://doi.org/10.1123/rsj.30.1.9

Weitzman, E., Nelson, T., \& Wechsler, H. (2003). Taking up binge drinking in college: The influences of person, social group, and environment. Journal of Adolescent Health, 32(1), 26-35. https://doi.org/10.1016/S1054-139X(02)00457-3

Weston, R., \& Gore, P. A. (2006). A Brief Guide to Structural Equation Modeling. The Counseling Psychologist, 34(5), 719-751. https://doi.org/10.1177/0011000006286345

Wood, W., \& Neal, D. T. (2009). The habitual consumer. Journal of Consumer Psychology, 19(4), 579-592. https://doi.org/10.1016/j.jcps.2009.08.003

World Health Organization. (2018). Noncommunicable diseases country profiles 2018. World Health Organization. 
Yen, H.-Y., \& Li, C. (2019). Determinants of physical activity: A path model based on an ecological model of active living. PLOS ONE, 14(7), e0220314. https://doi.org/10.1371/journal.pone.0220314

Yoon, A., Kim, K., \& Lee, S. (2014). The effects of residence on the eating and exercise habits of college freshmen in US. International Journal of Applied Sports Sciences, 26(1), 1-10. https://doi.org/10.24985/ijass.2014.26.1.1

Young, M. D., Plotnikoff, R. C., Collins, C. E., Callister, R., \& Morgan, P. J. (2014). Social cognitive theory and physical activity: A systematic review and meta-analysis. Obesity Reviews, 15(12), 983-995. https://doi.org/10.1111/obr.12225

Zizzi, S., Ayers, S. F., Watson, J. C., \& Keeler, L. (2004). Assessing the impact of new student campus recreation centers. Journal of Student Affairs Research and Practice, 41(4). https://doi.org/10.2202/1949-6605.1390

Zizzi, S., Keeler, L., \& Watson II, J. C. (2006). The interaction of goal orientation and stage of change on exercise behavior in college students. Journal of Sport Behavior, 29(1), 16. 